يستهدف هذا البحث بصفة رئيسية تقييم أثر البرنامج التليفزيوني الزراعي (حلقة وصل) المبث عبر قناة مصر الزبر اعبية

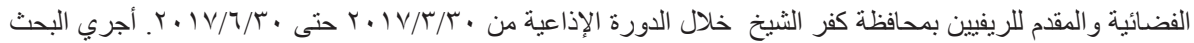

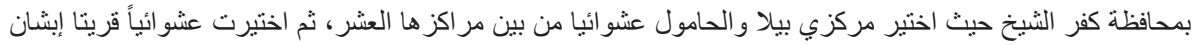

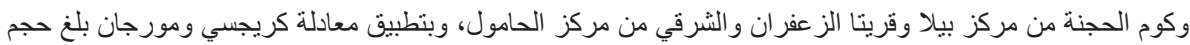

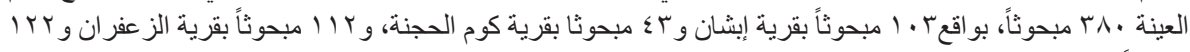

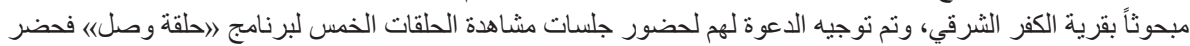

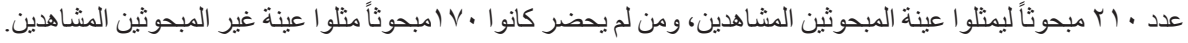

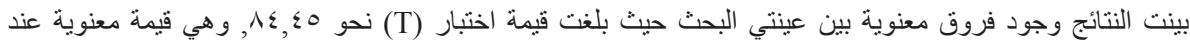

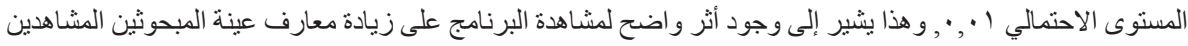

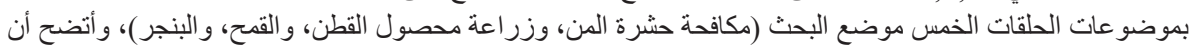

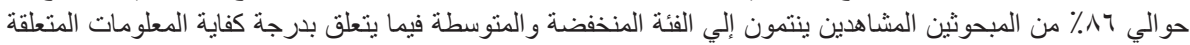
بمحتوي هذه الموضو عنات المبثة عبر البرنامج.

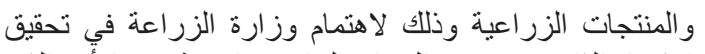

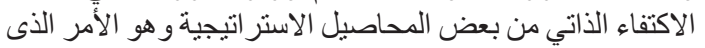

لم يتحقق بصورة كاملة حتى الآن رغم تلألك الجهود الحثئينة.

ويؤدى الإرشاد الزراعي دوره في تحديد مشاكل الريفيين

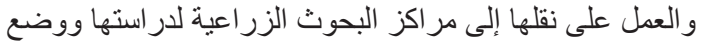

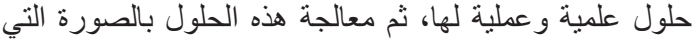

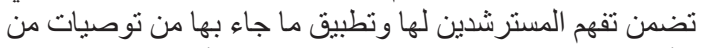

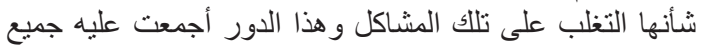

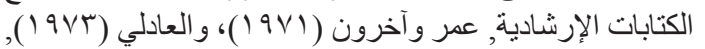

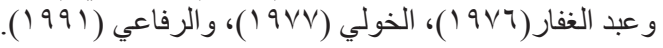

ومع التطور التكنولوجي في القطاع الزراعي وظهور العديد

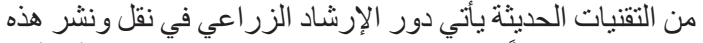

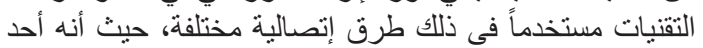

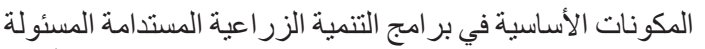

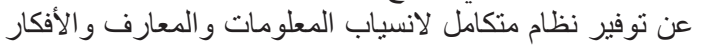

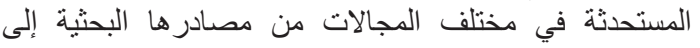

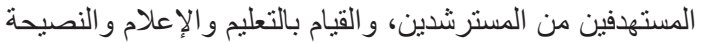

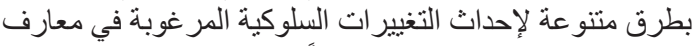

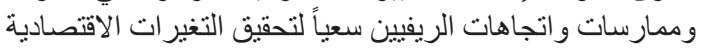

و الاجتماعية المنشودة (Swanson, 1990).

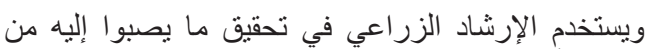

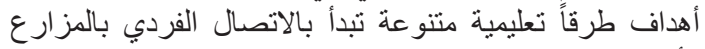

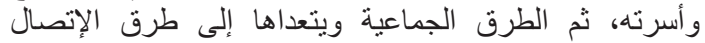
الجماهيري عن طريق الصحافة والإذاعة و التليفزيون.
المقدمة ومشكلة البحث

يتطلب قطاع الزراعة التحديث المستمر لتحقيق أقصى قدر

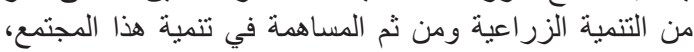

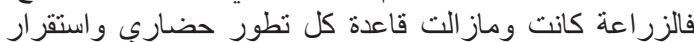
بشرى ورخاء لحياة الإنسان, وهى أم الصناعات كاعل وركيزتها.

ويعد قطاع الزر اعة في مصر أحد القطاعات المؤثرة بفاعلية

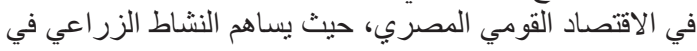

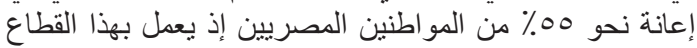

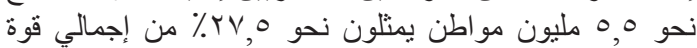

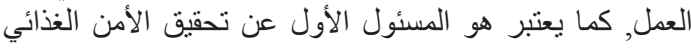

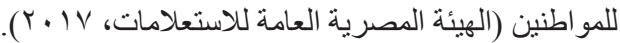

ويواجه القطاع الزراعي بالعديد من التحديات كمحدوية

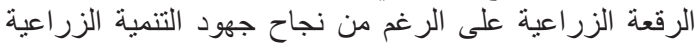

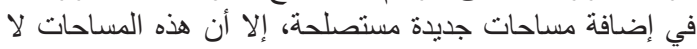

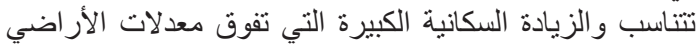

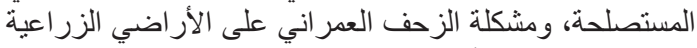

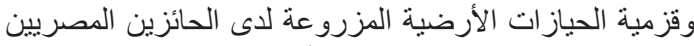

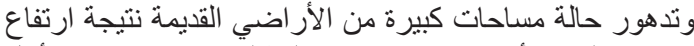

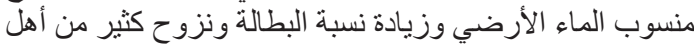

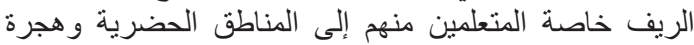

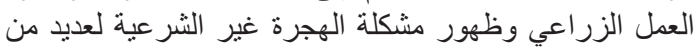

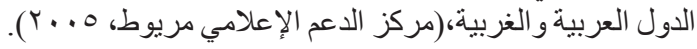
و على الرغم من ذلك فما زال القطاع الزر اعي يسهم بدور

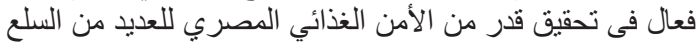

"Corresponding author: a_elhamoly@yahoo.com

DOI : 10.21608/jsas.2019.10296.1134

Received:6/3/2019;Accepted:8/6/2019

C2019 National Information and Documentation Center (NIDOC) 
ومقترحاتهم لتطوير البرنامج لتحقيق أكبر استفادة مكنة؟.

أهداف البحث

بينهدف هذا البحث بصفة رئيسية تقييم أثر البرنامج

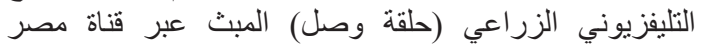

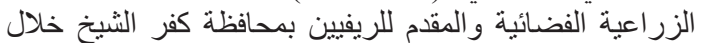

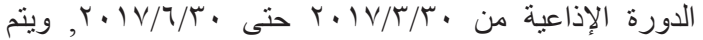
تحقيق ذللك من خلال الأهداف الفرعية التالية:

ـ التعرف على بعض الخصائص المميزة للمبحوثين المشاهدين

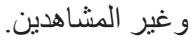

ـ التعرف على معارف المبحوثين المشاهدين وغير المشاهدين

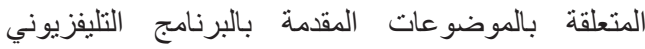

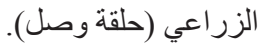

ـ التعرف على أثر البرنامج التلبفزيوني الزر اعي (حلقة وصل)

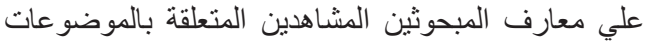

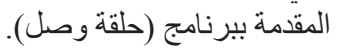

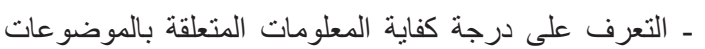

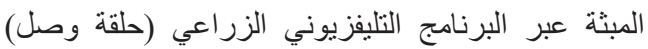

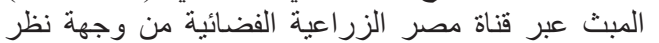

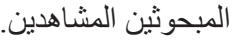

- تحديد أسباب عدم منابعة المبحوثين للبرنامج التليفزيوني

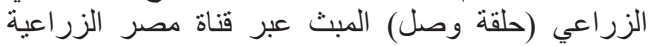
الفضائية، ومقترحاتهم لتطوير البرنامج لتحقيق أكبر استفادة الزية

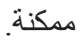
الاستعر اض المرجعي

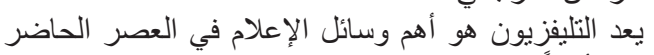

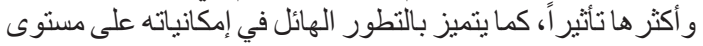

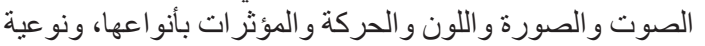

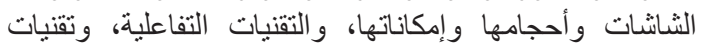

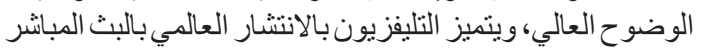

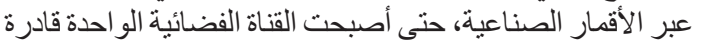

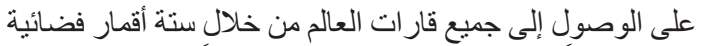

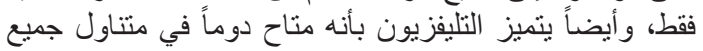

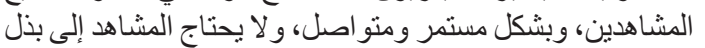

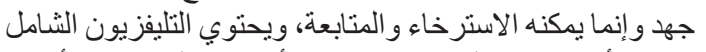

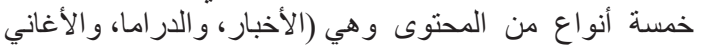

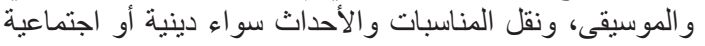

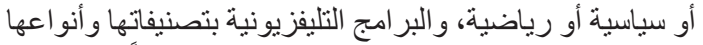

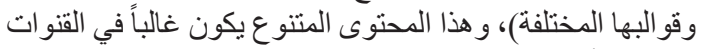

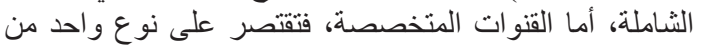

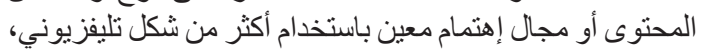

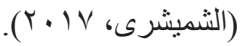

وتعتبر البرامج الريفية التليفزيونية من أهم الوسائل التى تئي

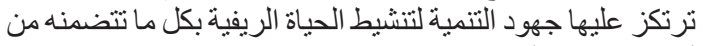

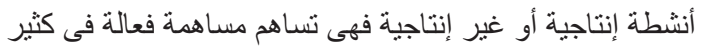

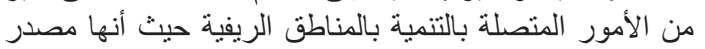

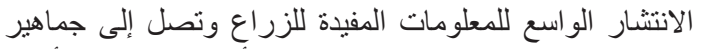

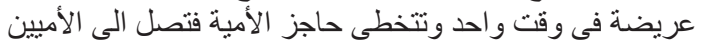

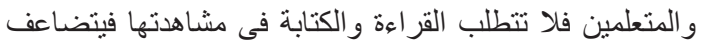
الأثر التعليمي لهذه البرامج الريفية التلبفزيونية.

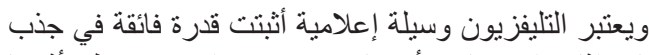

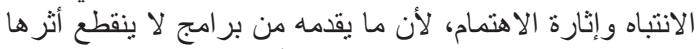

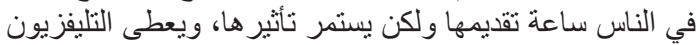

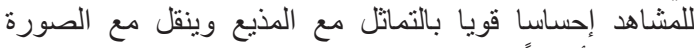

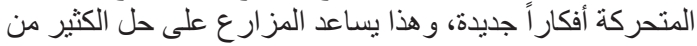

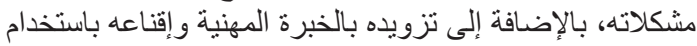

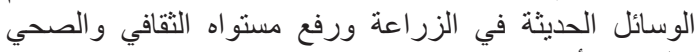

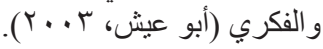

ويذكر عمر (9^19 (19) أن البرامج التليفزيونية الزراعية

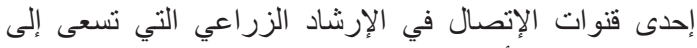

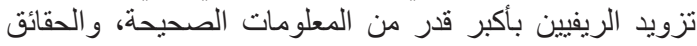

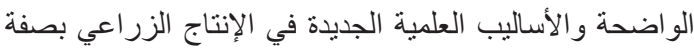

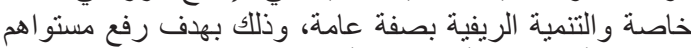

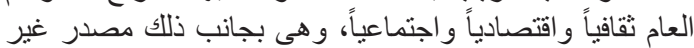
مكلف للمعرفة و الترفيه.

بالإضافة إلي أن البر امج التليفزيونية يمكن توظيفها في نشر

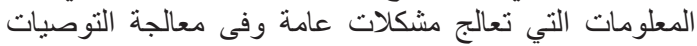

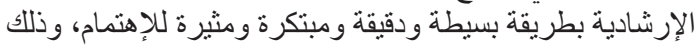

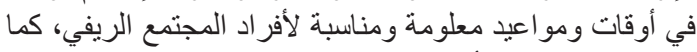

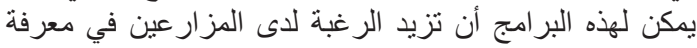

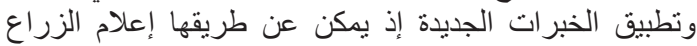

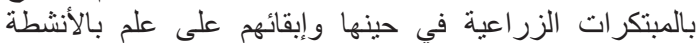

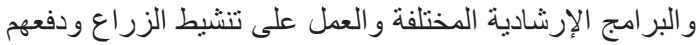

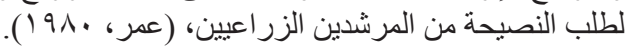

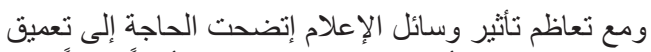

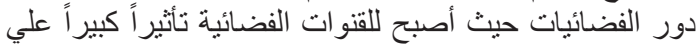

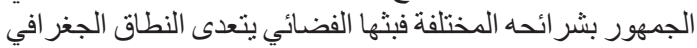

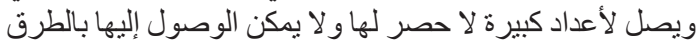

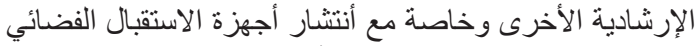

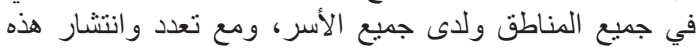

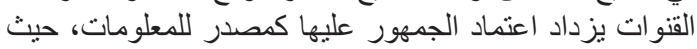

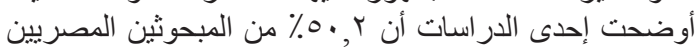

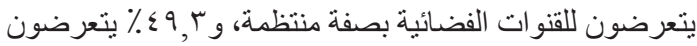

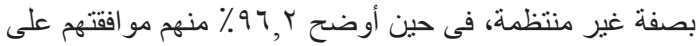

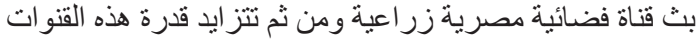

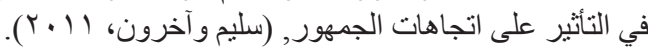

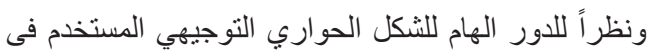

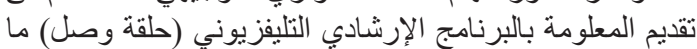

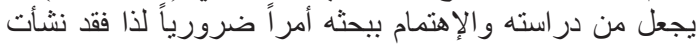

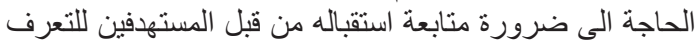

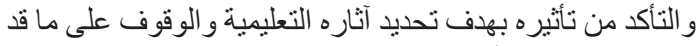
يعيق تحقيق هذا الأثر الإيجابي.

ولذلك فإن هذا البحث يسعى إلى تقييم أثر أحد البرامج امج

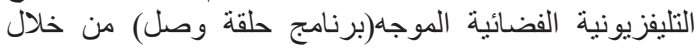

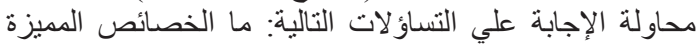

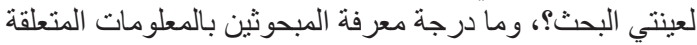

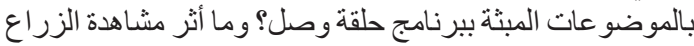

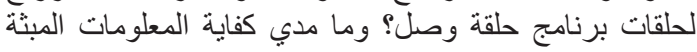

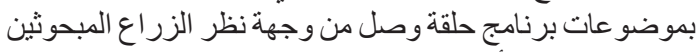

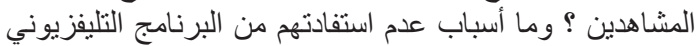
الزر اعي (حلقة وصل) المبث عبر قناة مصر الزر اعية الفضائية، 


$$
\text { المرشدين الزراعيين(عمر ، ·191) ). }
$$

ويذكر السيد (199 (1) أن البرامج الريفية التليفزيونية تهدف

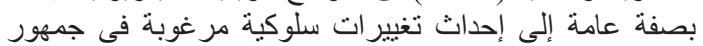

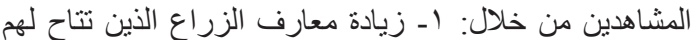

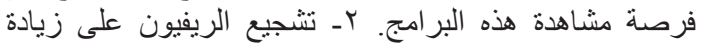

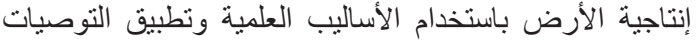

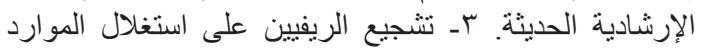

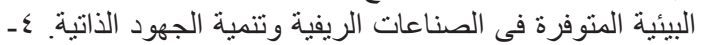

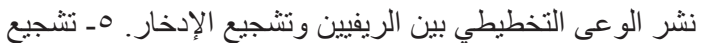

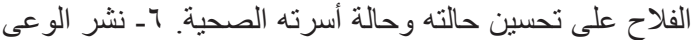

عن دور المنظمات الثعبية والأجهزة التنفيذية فى تنمية الترية.

ونستخلص مما سبق أن من الضروري أن تكون للبرامج

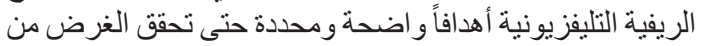
إعدادها وتقيمها للجمهور المستهدف.

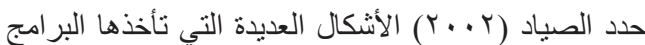
التليفزيونية ومن أهمها الآتي: الـالأخبار : ويقصد بها الغنطية أخبار

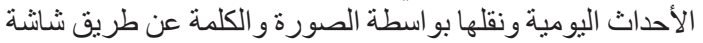
التليفزيون, وتعتمد برامج الأخبار في التلتيفزيون اعتماداً أساسياً

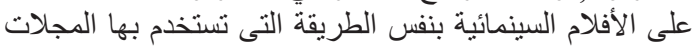

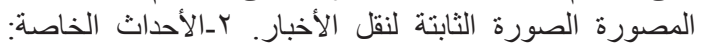
يقصد بها الأحداث المتعلقة بالمناسبات ذات الألهات الهمية الخاصة مثل

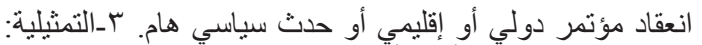

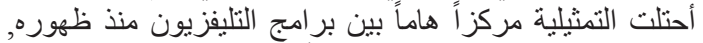

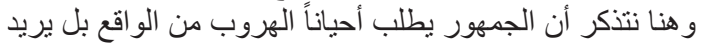

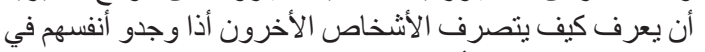
المو اقع التي تكون مألوفة لهذا الجمهور. ع ـالبرن البرنامج التسجيلي:

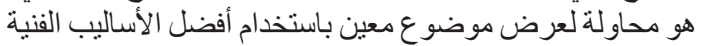

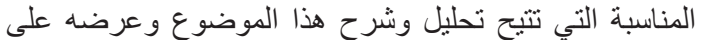
الشاهدين فى صورة مناسبة تجذب انتباههم وتثير خيالهم.

ولكى تتجح البرامج التلبفزيونية الريفية فى تحقيق أهدافها

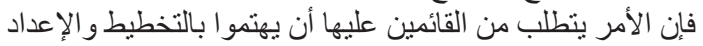

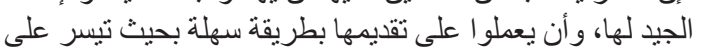

مشاهديها فهم واستيعاب ما تتضمنه من توجيهات تخدية تخدم التنمية.

ويجب أن يقوم تخطيط البرامج الريفية التلايفزيونية على

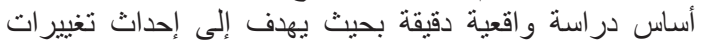

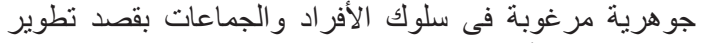
وتحسين جميع أحو الهم المعيشية.

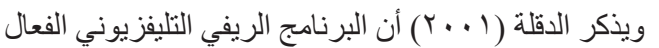

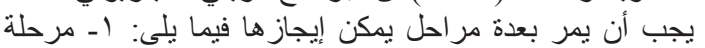

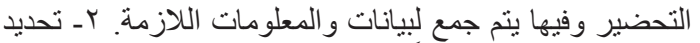

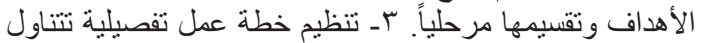

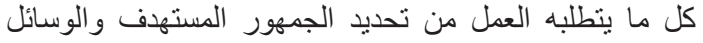

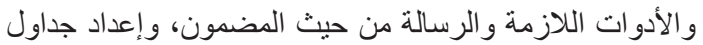

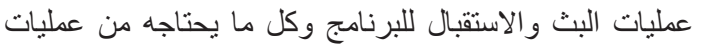

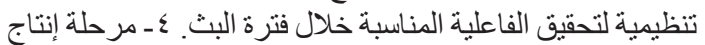

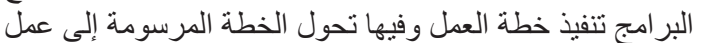

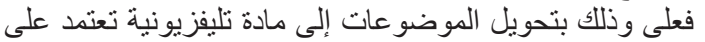

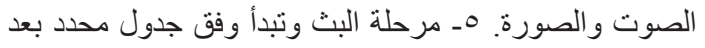

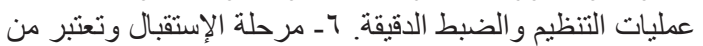

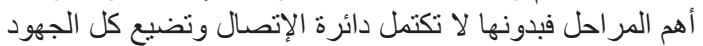

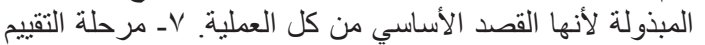

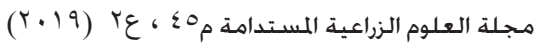

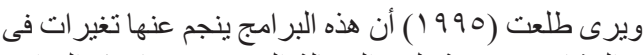

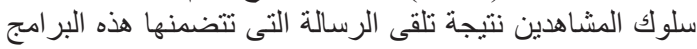

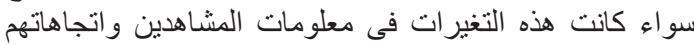

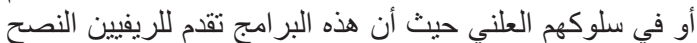

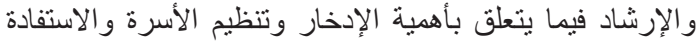

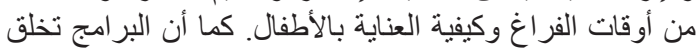

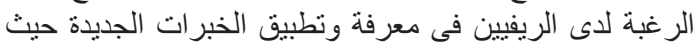

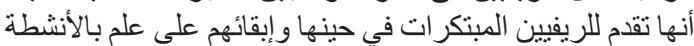

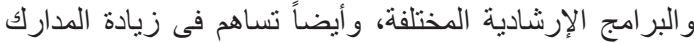

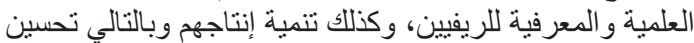

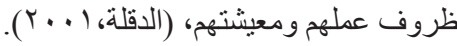

وتصنف البرامج التلفزيونية عبر عدة معايير على النحو الإني

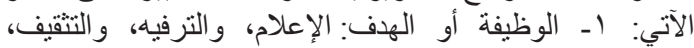

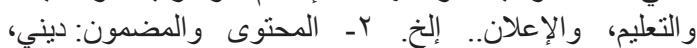

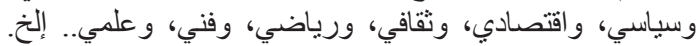

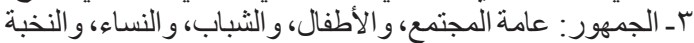

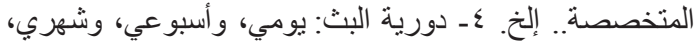

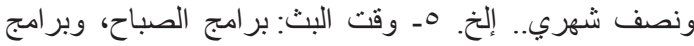

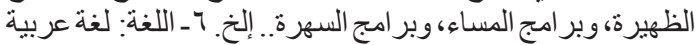

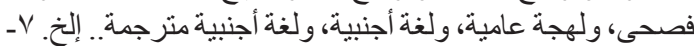

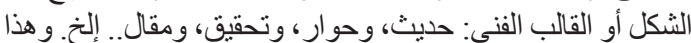

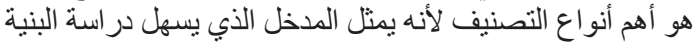

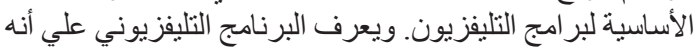

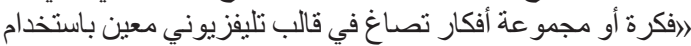
الصورة والصوت بكامل تفاصيلها الفنية لتحقيق هدف معينشي.

و هنالك عدة قو الب من البر امج التلبفزيونية: الـ ـ قالب الحديث

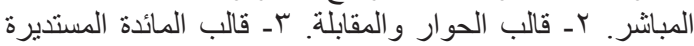

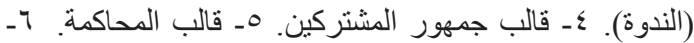

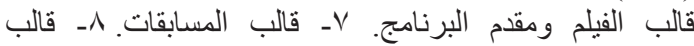

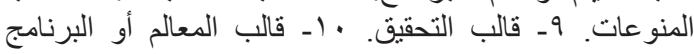
الخاص. ال إ قالب المجلة التليفزيونية.

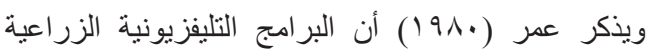

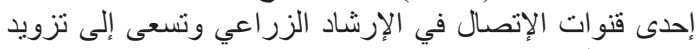

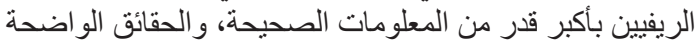

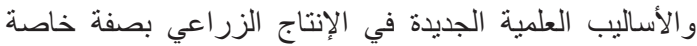

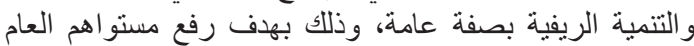

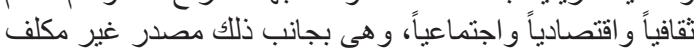

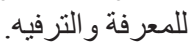

ويمكن استخدام جميع البرامج التليفزيونية الزراعية بكافة

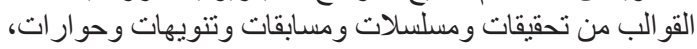

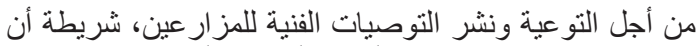

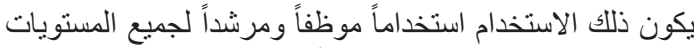
الاقتصادية والاجتماعية للزراع واع وأن تركز التوعية علية على الفائدة التي سيجنيها المز ارع من هذاعة التغيير.

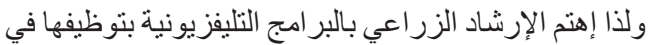

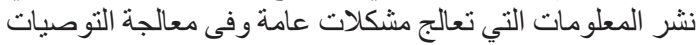

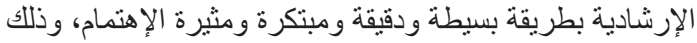

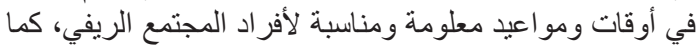

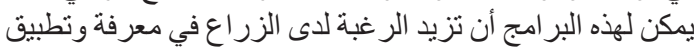

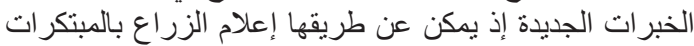

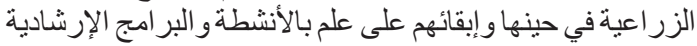

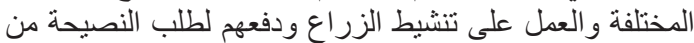


المحاصيل والصادرات الزراعية. بـ تقديم الخدمة الإرشادية

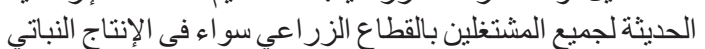

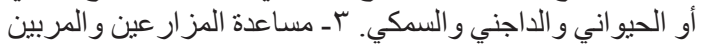

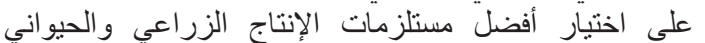

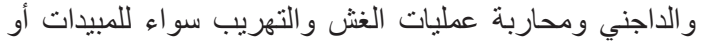

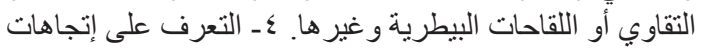

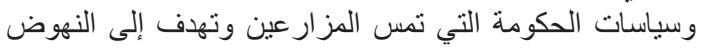

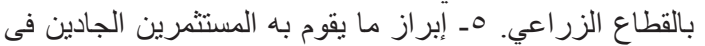

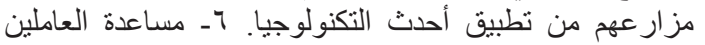

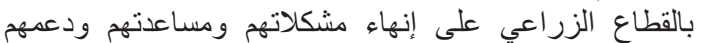

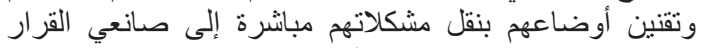

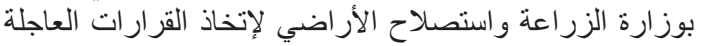

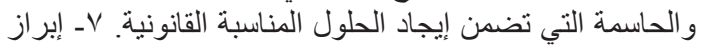

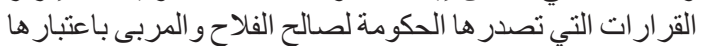

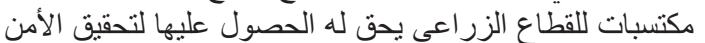

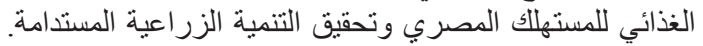

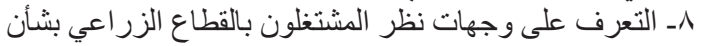
القرار ات الحكومية لضمان استفادتهم الكاملة بها.

و أجريت بعض الدراسات في هذا الصدد كدراسة غازي

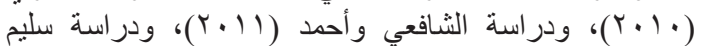

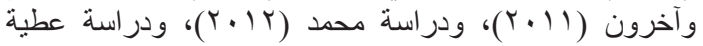

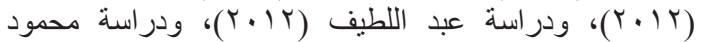

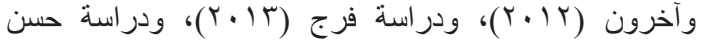

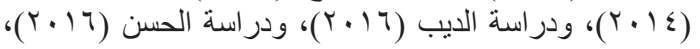

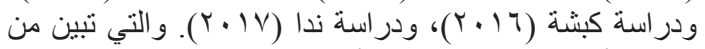

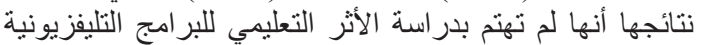

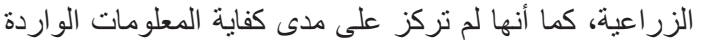

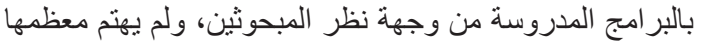

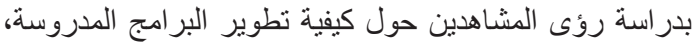
و عليه فإن هذه النقاط سوف تكون منطلقات للبحث التالي.

\section{الأسلوب البحثي}

يتناول هذا الجزء توضيحاً للإجر اءات البحثية التي تم تتفيذها

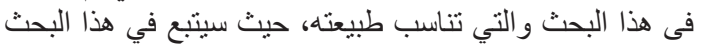

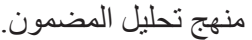

أولاً: اختيار وتفريغ حلقات البرنامج التليفزيوني الزر اعي الحلقة

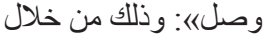

- حصر جميع حلقات البرنامج (حلقة وصل) من خلال الخريطة

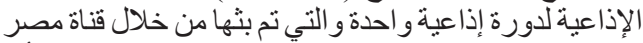

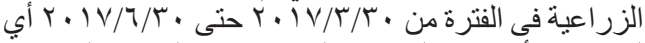

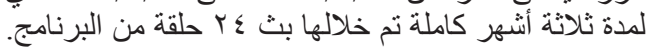

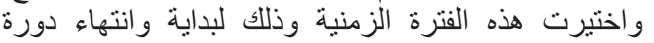

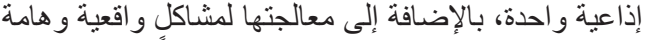

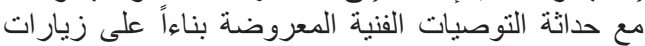
استكثافية إلى منطقة البحث (جدول الفية المعرولة ).

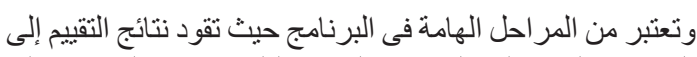

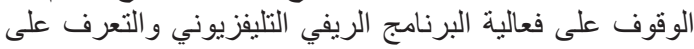
جو انب القوة و الضعف فئه النيه

بينما يوجز حواس ( ( . ب) أوجه قصور البر امج الإرشادية

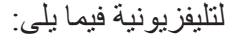

1 ـ لا تتيح فرصة التفاعل الاجتماعي مع المسترشدين حيث يقفون

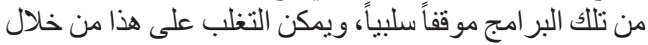

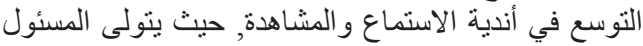
عن النادي مناقشة أعضاءه عقب العرض التليفزيوني.

r- يتطلب إعداد و إخر اج البرامج التليفزيونية الريفية مجهودات

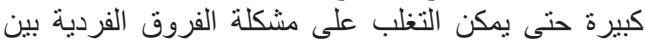

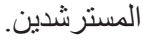

r- قد يصعب تحقيق بعض الجوانب فى المحتوى الإرشادي عن طريق البر امج التليفزيونية.

ع ـ تتطلب من المشاهدين انتباهاً أكبر مما تتطلبه البر امج الإذاعية. 0- يهتم كثير من المسترشدين بمتابعة البرامج الترفيهية دون

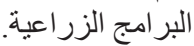

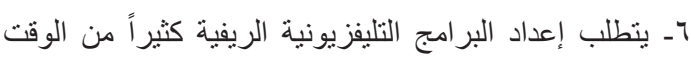

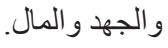

V- V ل تفيد البرامج التليفزيونية كثير اً فى تحقيق بعض الأهداف

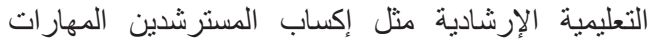

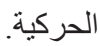

وتعتبر وسائل الإعلام المسمو عة والمرئية ذات نأثنير كبير

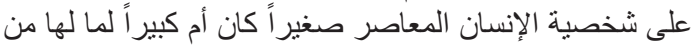

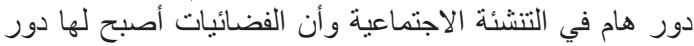

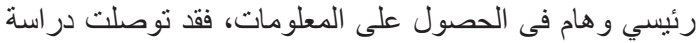

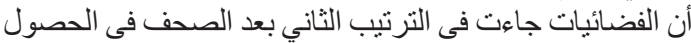

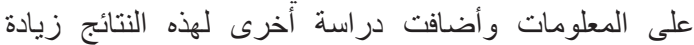

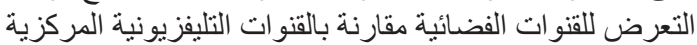

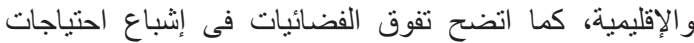

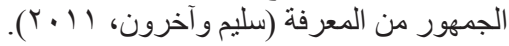

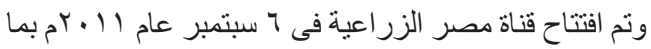

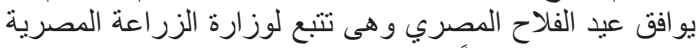

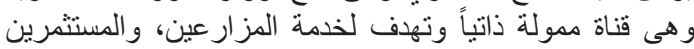

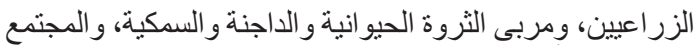

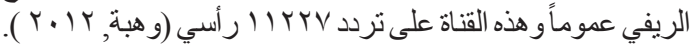

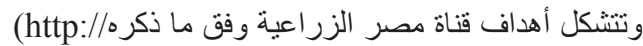
www.misraIzraya.tv@com), 2015 المصري و الاهتمام به وحل جميع المعوقات التي تو اجهه لزيادة داحة

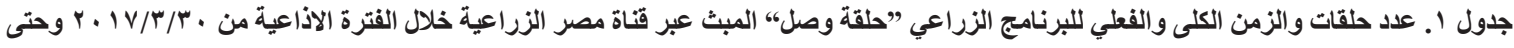
$r \cdot 1 \mathrm{~V}, \mathrm{r} / \mathrm{r}$.

\begin{tabular}{|c|c|c|c|c|c|}
\hline \multirow[b]{2}{*}{ الزمن الكلي للحلقات المختارة بالدقيقة } & \multirow[b]{2}{*}{ زمن الحلقة بالدقيقة } & \multicolumn{2}{|c|}{ عدد حلقات البرنامج } & \multirow[b]{2}{*}{ اسم البرنامج } & \multirow[b]{2}{*}{ م } \\
\hline & & المختارة & الكلية & & \\
\hline vo & 10 & 0 & ir & حلقة وصل & 1 \\
\hline
\end{tabular}




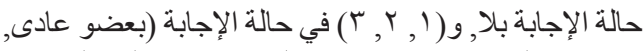
عضو مجلس إدارة, رئيس مجلس إدارة) وجمعت الدرجة لتعبر عن درجة المبحوث في في الدارة عذا المتغير.

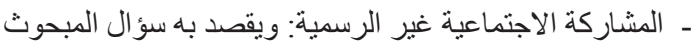

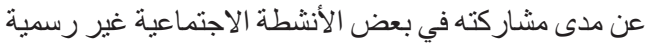

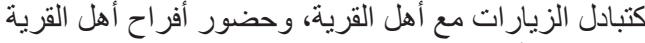

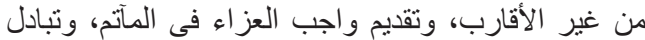

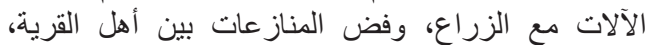

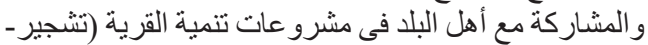

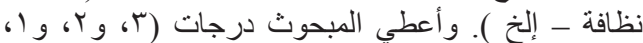

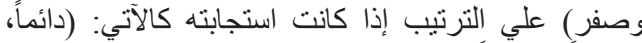

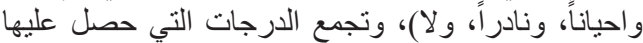

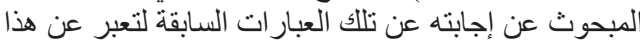

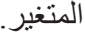

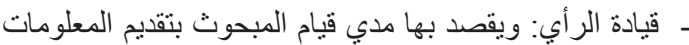

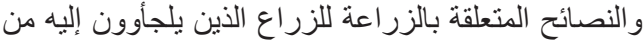

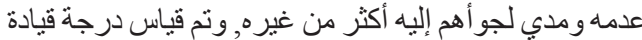

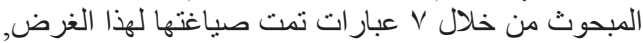

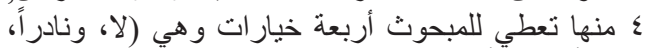

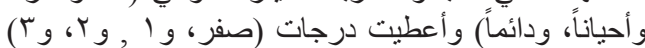

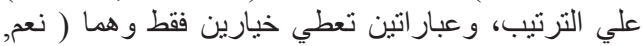

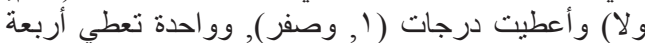

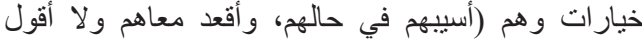

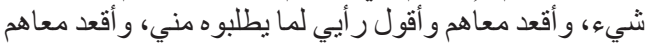

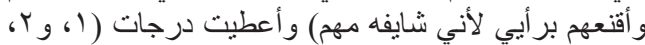

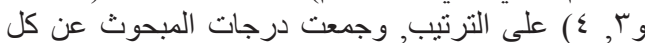
عبارة لتعبر عن درجة المبحتب وجمعث في هذا المتغير.

ـ التجديدية: ويقصد بها درجة استعداد المبحوث وأسبقيته لتنفيذ

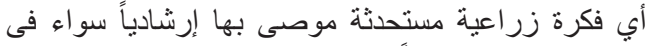

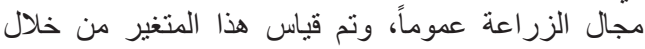

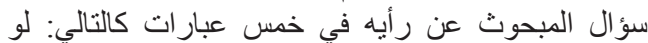

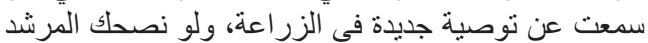

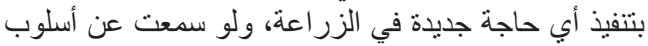

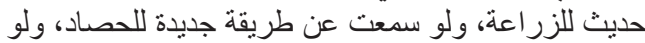

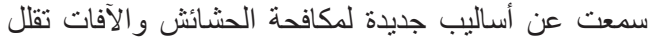

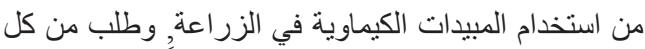

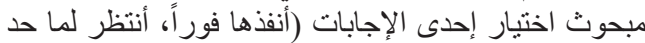

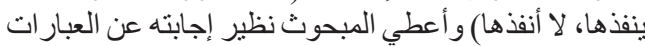

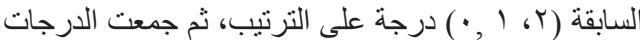

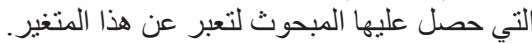

- درجة معرفة المبحوث بالبنود المعرفية المتعلقة بموضوعات

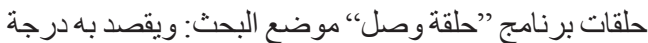

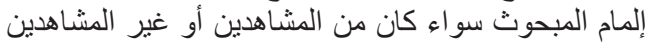

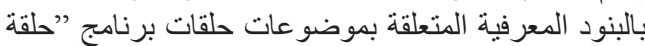

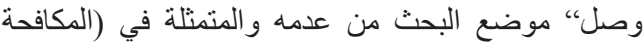

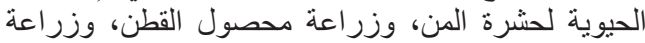

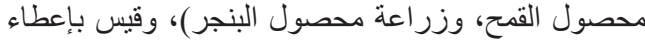

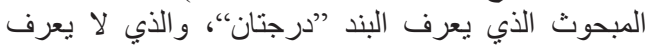

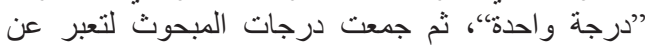

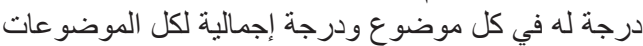

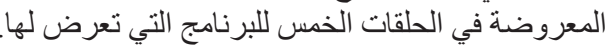

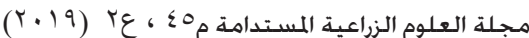

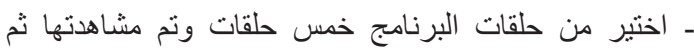

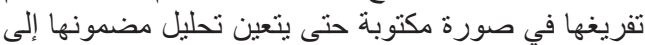

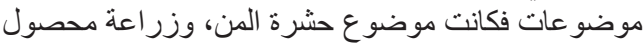

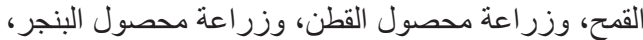

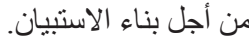

ثانياً: التعاريف الإجر ائية وقياس المتغيرات:

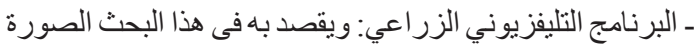

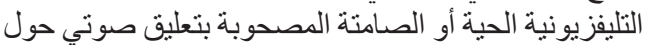

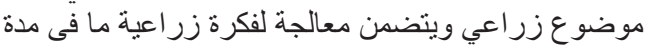

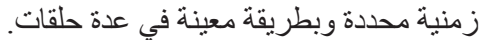

- برنامج حلقة وصل: ويقصد به في هذا البحث البرنامج

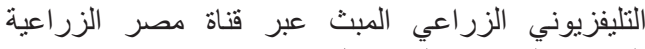
الفضائية المسمى بحلقة وصل.

- سن المبحوث: ويقصد به عمر المبحوث حتي وقت تجميع

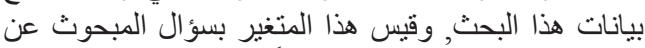
سنه حتي وقت إجر اء البحث مقدر أ بعدد السنين.

- تعليم المبحوث: ويقصد به مدي قدرة المبحوث علي القراءة

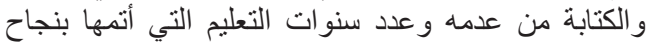

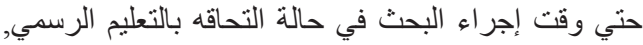

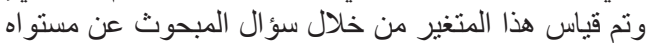

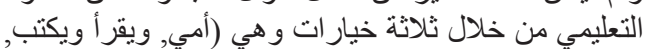

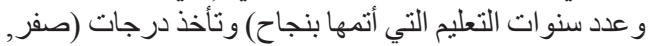
و (, ودرجة لكل سنة دن سنوات التعليماتيم التي أتمها بنجاح)

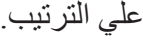

- السعة الأسرية: يقصد بها عدد الأفراد الذين تتكون منهم أسرة

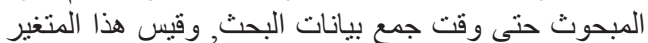

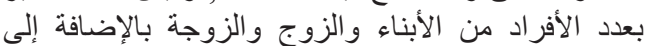
الأفر اد الآخرين الذين يعيشون مع المبحوث في وحدة ولاء معيشية

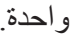

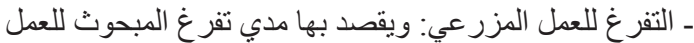

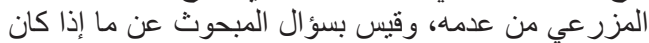

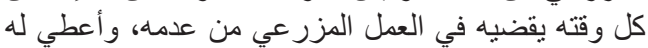

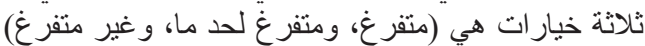

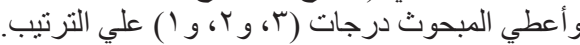

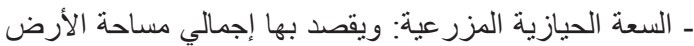

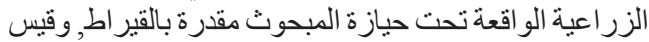

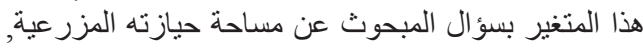
وتم قياسها بالقير اط.

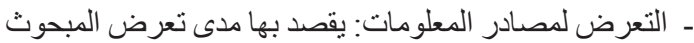

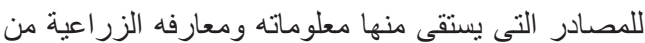

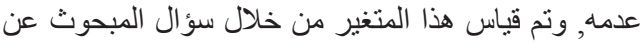

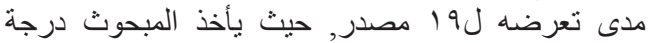

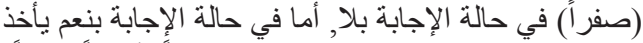

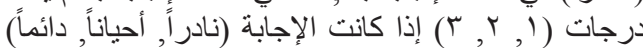
على الترتيب

ـ المشاركة الاجتماعية الرسمية: يقصد بها مدى مشار كة المبحوث

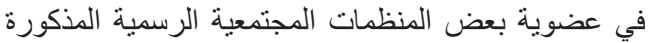

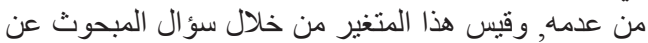
مدى مشاركته في عدة منظمات اجنماعية، فيأخذ (صفراً) في الفي 


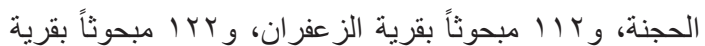
الكفر الثرقي، و أخذت كل عينة بطريقة عشو ائية بسيطة.

ونظراً لطبيعة هذا البحث وبعد زيار ات استكثافية لمنطقة

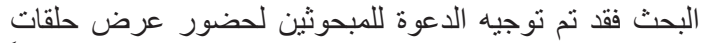

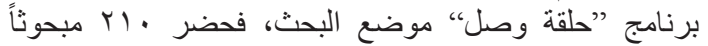

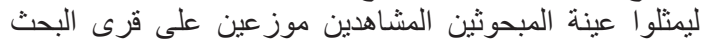

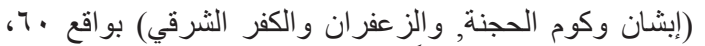

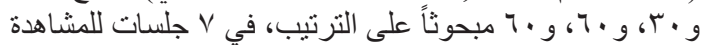

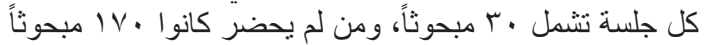

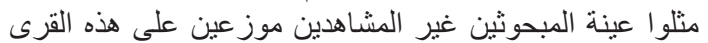

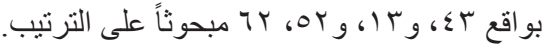

سادساً: إعداد و اختبار إستمارة الاستبيان:

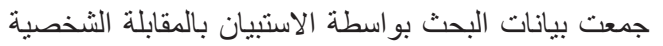

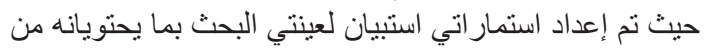

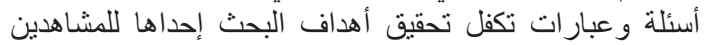

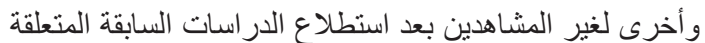
بموضوع البحث، وتضمنت كل إستمارة ثلاثة أجز اء وهي:

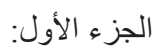
ويشتمل علي مجمو عة من الأسئلة المتعلقة ببعض الخصائص

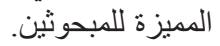

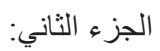
ويشمل الاختبار المعرفي لتحديد أثر البرنامج التليفزيوني

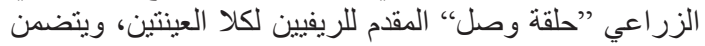

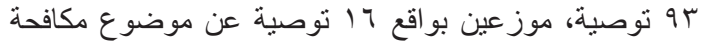

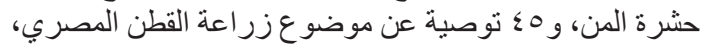

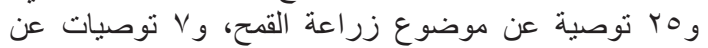

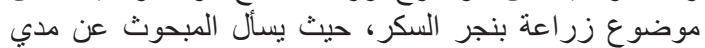

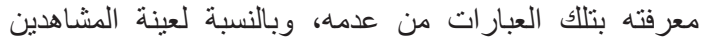

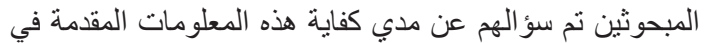

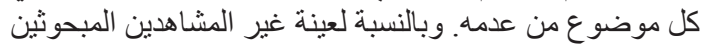

الذين يعرفون التوصية تم سؤ الهم عن مصدر معرفتهم بها. الجزء الثالث: - الثن

ويتضمن رأى المشاهدين المبحوثين فى حلقات البرنامج

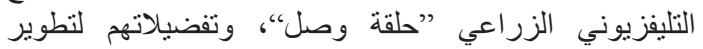

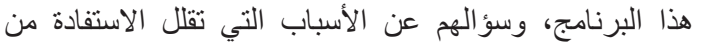

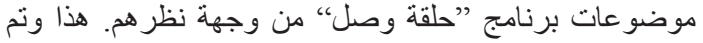
إجر اء اختبار مبدئى (Pre-test) لاستمارة الاستبيان على على عينة

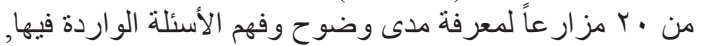

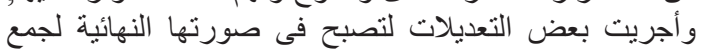
البيانات.

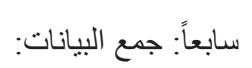

جمعت بيانات هذا البات البحث من جميع المبحوثين بواسطة

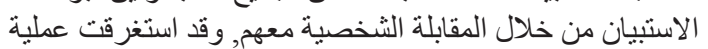

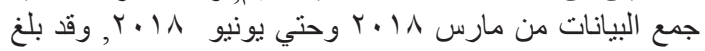

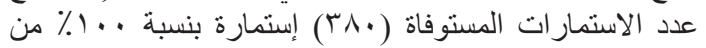
عينة البحث.

ثنامناً: تحليل البيانات:

بعد جمع البيانات تم مراجعة إستمار ات اتبات الاستبيان ميدانياً

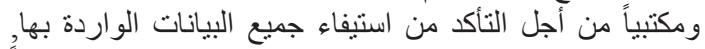

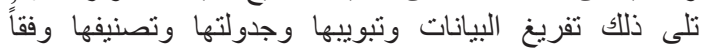

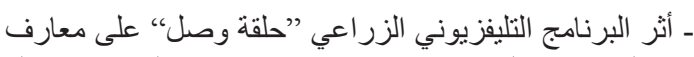

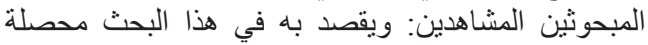

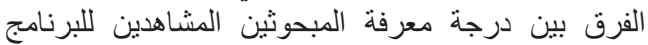

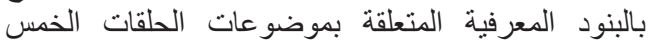

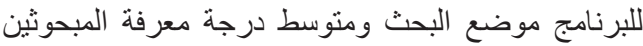

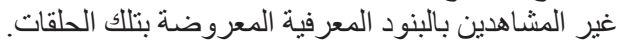

- درجة كفاية المعلومات المتعلقة بالموضوعات المعروضة

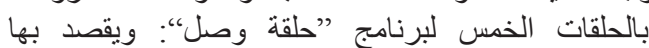

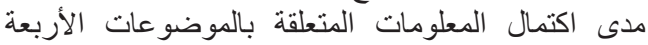

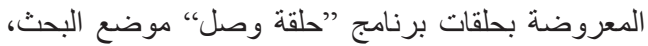

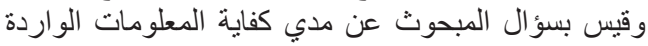

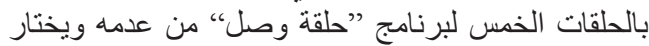

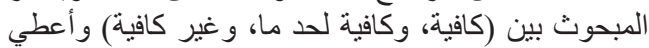

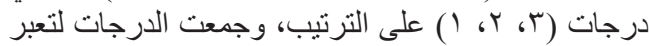

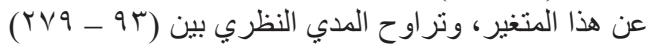

درجة.

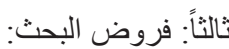

تحقيقاً لهدف البحث الثالث, تم صباغة فرض فرض البحث كما يلي:

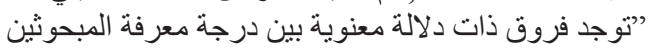

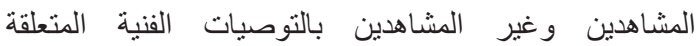
بموضو عات حلقات برنامج حلقة وصل موضئ بوضع البحث و المتمثلة

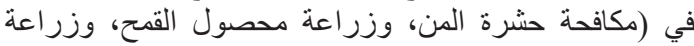
محصول القطن، وزر اعة محصول وزلة البنجر).

وقد نم اختبار هذا الفرض في صورته الصفرية.

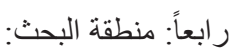

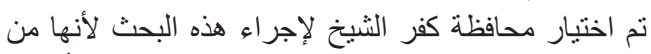

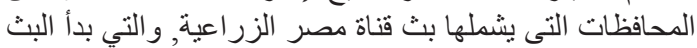

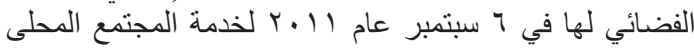

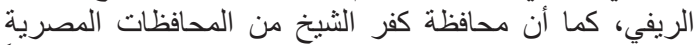

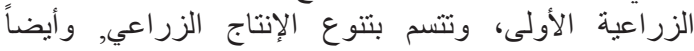

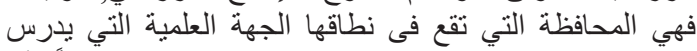

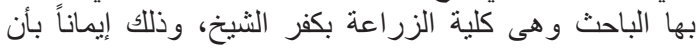

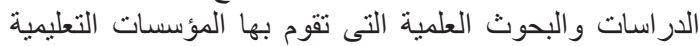

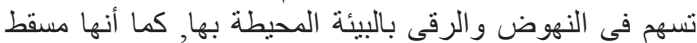

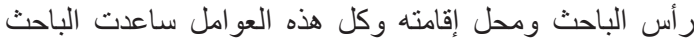

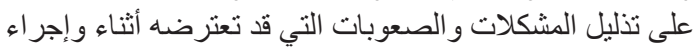

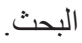

هذا وتتكون محافظة كفر الثيخ من عشر مراكز إدارية

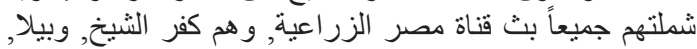

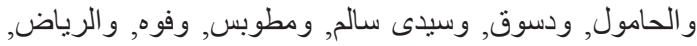

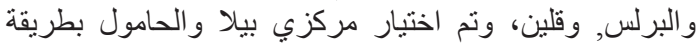

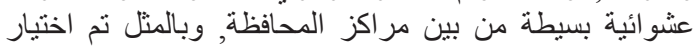

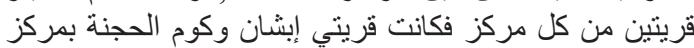
بيلا, وقريتي الزعفران و الكفر الثرقي بمركز الحامول.

خامساً: شاملة و عينة البحث:

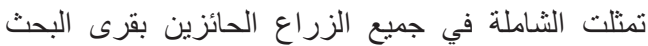

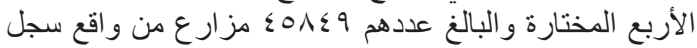

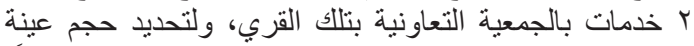

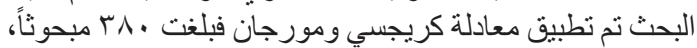

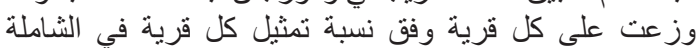

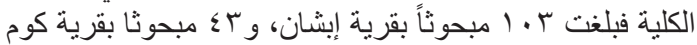

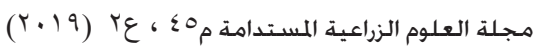


و اتضح أن Yo, \% من عينة المبحوثين المشاهدين في فئة

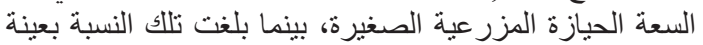

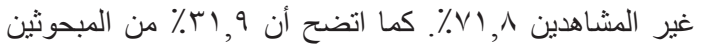

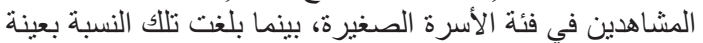

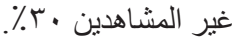

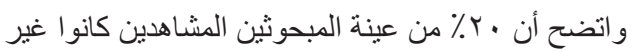

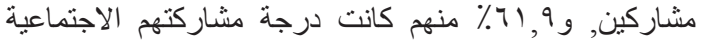

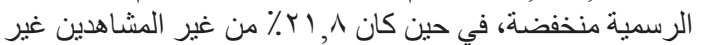

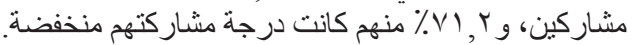

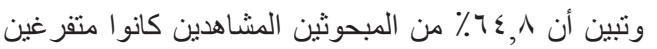

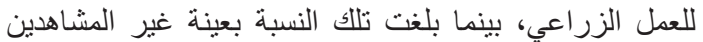

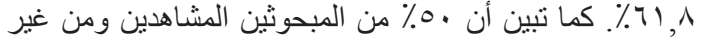

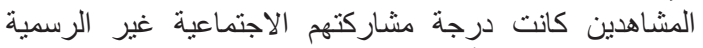

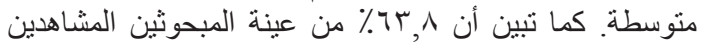

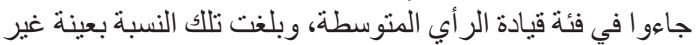

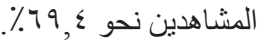

لمنطلبات البحث, وتم إدخال البيانات وتحليلها باستخدام البرنامج

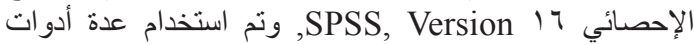

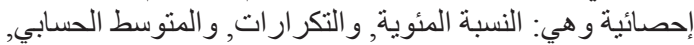

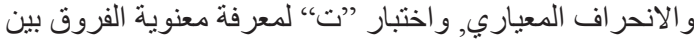

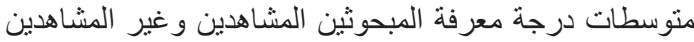

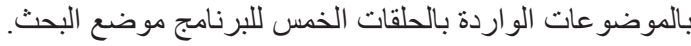

النتائج البحثية ومناقثتنها

أولاً: بعض الخصائص الممبزة لعينتي البحث المشاهدين وغير

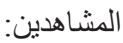

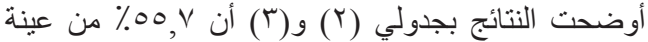

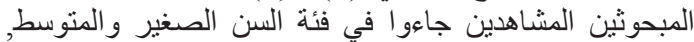

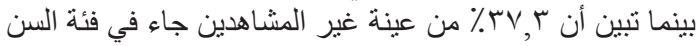

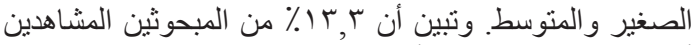

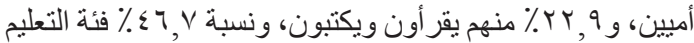

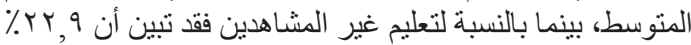

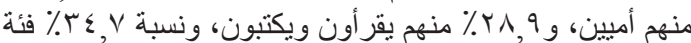

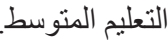

جدول ץ. توزيع عينة المبحوثين المشاهدين لبرنامج 》حلقة وصله) وفقاً لبعض خصائصهم الممبزة

\begin{tabular}{|c|c|c|c|c|c|}
\hline$\%$ & عدد & الخصائص & $\%$ & عدد & الخصائص \\
\hline \multicolumn{3}{|c|}{ التفرغ للعمل المزرعى } & \multicolumn{3}{|c|}{ سن المبحوث } \\
\hline$T \varepsilon, \wedge$ & 4ra & متفرغ (r) درجات & $r_{0, V}$ & $0 \leqslant$ & صغير (r \\
\hline$r \cdot, \cdot$ & 70 & متفرغ الى حد ما (ץ) درجتين & $r \cdot, \cdot$ & זי & متوسط (0ب - ^^) سنة \\
\hline$\varepsilon, r$ & 9 & غير متفرغ (1) درجة واحدة & $\varepsilon \varepsilon, r$ & $q 4$ & كبير (q § - . 7) سنة \\
\hline \multicolumn{2}{|c|}{$r, r}$. & المنوسط الد & \multicolumn{2}{|c|}{$\varepsilon \varepsilon, \cdot 9$} & المتوسط الحسابي \\
\hline \multicolumn{2}{|c|}{$\cdot, \mathrm{OV}$} & الانحراف الم & \multicolumn{2}{|c|}{11,44} & الانحراف المعياري \\
\hline \multicolumn{3}{|c|}{ المشاركة الاجتماعية الرسمية } & \multicolumn{3}{|c|}{ تعليم المبحوث } \\
\hline \multirow[t]{2}{*}{$r_{\cdot}, \cdot$} & $\varepsilon r$ & غير عضو & r & rA & \\
\hline & & عضوية: & $r, q$ & $\leqslant \wedge$ & يقراً ويكتب \\
\hline 71,9 & ir. & منخفضة (1-ع) درجة & $0, V$ & ir & متعلم: منخفض ( ) (- ד سنوات \\
\hline 15,9 & iv & متوسطة (1-9) درجة & $\leqslant 7, V$ & $9 \wedge$ & متوسط (9-r ا ) سنة \\
\hline 0,5 & 11 & مرتفعة (·• آرا) درجة & $11, \varepsilon$ & $r \varepsilon$ & مرتفع ( ع ا-77 1) سنة \\
\hline \multicolumn{2}{|c|}{$r, \Sigma r$} & المتوسط الحد & \multicolumn{2}{|c|}{$\wedge, \cdot \vee$} & المتوسط الحسابي \\
\hline \multicolumn{2}{|c|}{ r,qv } & الانحـراف الما & \multicolumn{2}{|c|}{$0, r \varepsilon$} & الانحراف المعياري \\
\hline \multicolumn{3}{|c|}{ قيادة الرأي } & \multicolumn{3}{|c|}{ السعـة الحيازية المزرعية } \\
\hline $\mid r, \varepsilon$ & צד & منخفضة (v - - 1) درجات & $10, \mathrm{~V}$ & Ire & صغيرة (ז--ع) قيراط \\
\hline r ו & $1 \pi \varepsilon$ & متوسطة (11 - 10) درجة & $r \cdot, \cdot$ & $\pi$ & متوسطة (ا乏-1^) قيراط \\
\hline$r$ r & 0 . & مرتفعة (17 - 19) درجة & $\varepsilon, r$ & 9 & كبيرة (זی - · I ) قيراط \\
\hline \multicolumn{2}{|c|}{$|r, \pi|$} & المتوسط الد & \multicolumn{2}{|c|}{$r \eta, \wedge r$} & المتوسط الحسابي \\
\hline \multicolumn{2}{|c|}{$r, V Y$} & الانحراف الد & \multicolumn{2}{|c|}{10,09} & الانحـراف المعياري \\
\hline \multicolumn{3}{|c|}{ التعرض للمصادر المرجعية } & \multicolumn{3}{|c|}{ السعة الأسرية } \\
\hline$\mu r, \varepsilon$ & 11 & منخفضة (.1 - 19) درجة & $r 1,9$ & iv & صغيرة (ז-r) أفراد \\
\hline$\Delta \varepsilon, v$ & 110 & متوسطة (·r - זr) درجة & $\Delta 9,0$ & 150 & متوسطة (乏-7)أفراد \\
\hline 15,9 & iv & مرتفعة (س - I آ) درجة & $\wedge, 1$ & 11 & كبيرة (A-V) افراًد \\
\hline \multicolumn{2}{|c|}{$i r$,$\rceil .$} & المتوسط الح & \multicolumn{2}{|c|}{$r, r \varepsilon$} & المتوسط الحسابي \\
\hline \multicolumn{2}{|c|}{$v, r 1$} & 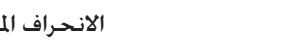 & \multicolumn{2}{|c|}{$1,0 \mathrm{r}$} & الانـــراف المعياري \\
\hline \multicolumn{3}{|c|}{ التجديدية } & \multicolumn{3}{|c|}{ المشـاركة الاجتماعية غير الرسمية } \\
\hline 19,0 & « & منخفضة (r - ه) درجات & $r \wedge, 1$ & $\wedge$. & منخفضة (1 - 9) درجات \\
\hline 11,9 & irt & متوسطة (1 - (^) درجات & $\Delta \cdot$, & 1.0 & متوسطة ( . 1 ع ) درجة \\
\hline$I V, 1$ & rv & مرتفعة (9 - . 1) درجات & 11,9 & ro & مرتفعة (10 - 1 1) درجة \\
\hline \multicolumn{2}{|c|}{$1, \mathrm{VA}$} & المتوسـط الح & \multicolumn{2}{|c|}{$1 \cdot, \mathrm{v} 1$} & المتوسـط الحسـابي \\
\hline $1,0 \varepsilon$ & & نانحراف بال & & & صدر : حسبت من استمار اتِ الاريّا \\
\hline
\end{tabular}

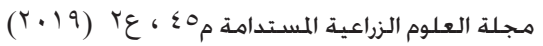


جدول r. توزيع عينة المبحوثين غير المثاهدين لبرنامج ”حلقة وصل، وفقاً لبعض خصائصهم المميزة

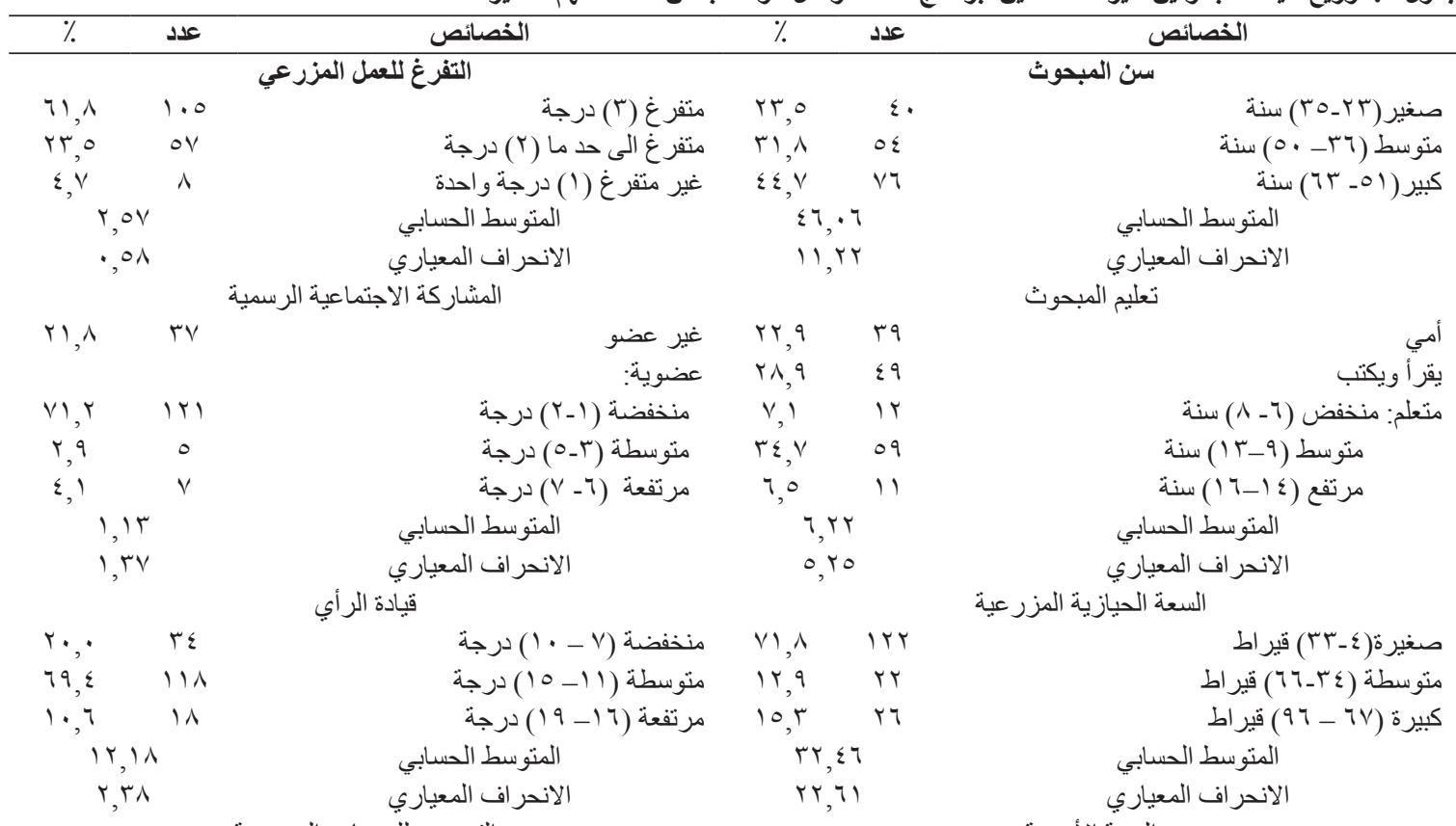

التعرض للمصادر المرجعية

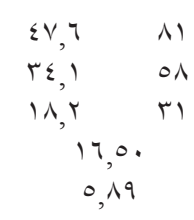

ri,

$r, r \quad 1 \cdot \varepsilon$

$\mathrm{r}, \quad$ ir

$7, r$.

I, YV
منخفضة (1) - ع ( ) درجة

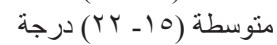

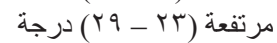

المتوسط الحسابي

الانحر اف المعياري

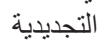

منخفضة (ع - 0) درجة

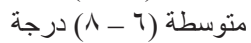

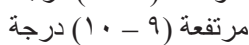

الإنتوسط الحسابي

الانحر اف المعياري

V.=ن

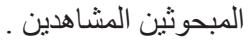

بينما بالنسبة للمبحوثين غير المشاهدين فجاء في فئة المعرفة

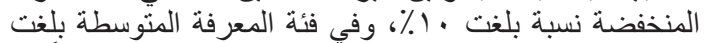

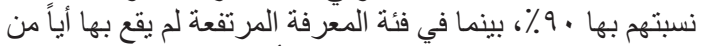

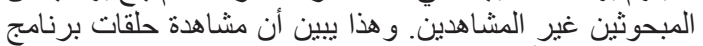

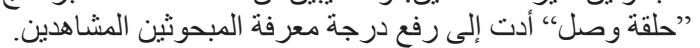

وتظهر النتائج السابقة أن قرابة ثلني المبحوثين المشاهدين

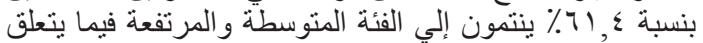

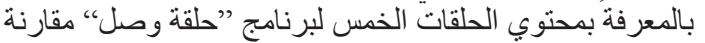

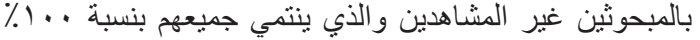

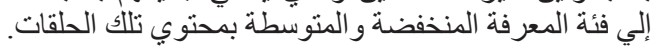

ب - معنوية الفروق بين منوسطات درجات معرفة المبحوثين

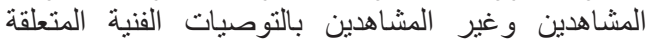

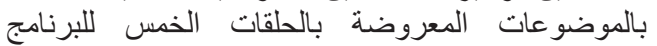

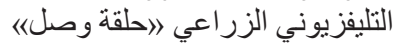

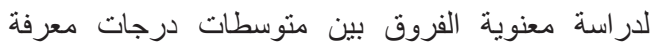

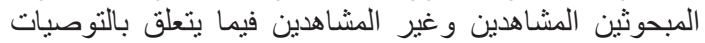

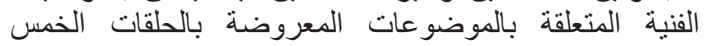

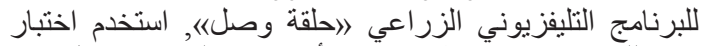

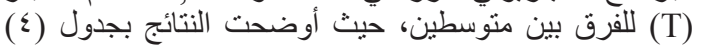

$r \cdot, \quad 01$

Vo,,$\quad q 1$

Ir, $\varepsilon \quad r \mid$

r, I $\leq$

I, Tr

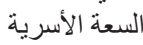

الانحر اف المعياري

المنوسط الحسابي الانحر اف المعياري

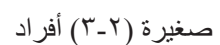

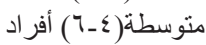

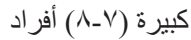
المشاركة الاجتماعية غير الرسمية

$\begin{array}{ll}0 \cdot, & \text { 10 } \\ \varepsilon 0, r & V V \\ \varepsilon, V \quad & 1 \\ 9, \lambda r & \\ 1,94 & \end{array}$

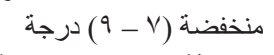
متوسطة (·1 - r ا (1) درجة

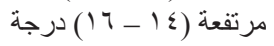
المنتوسط الحسابي الانحر اف المعياري

المصدر : حسبت من إستمار ات الاستبيان

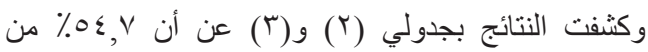

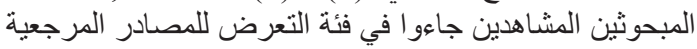

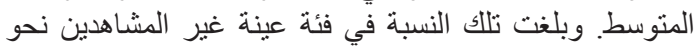

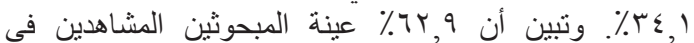

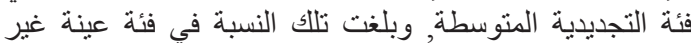

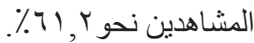

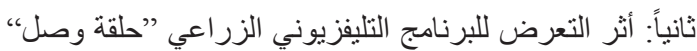

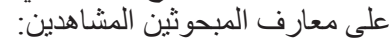

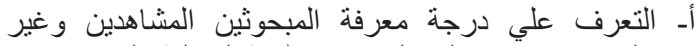

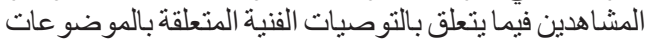

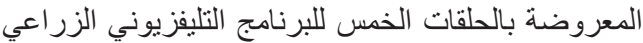

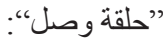

أشارت النتائج بشكل (1) إلى أن الدرجات النظرية المعبرة

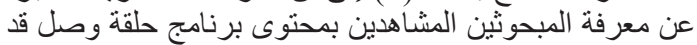

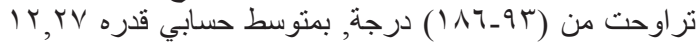

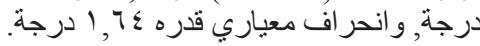

وبتقسيم المبحوثين المشاهدين إلي ثلاث فئات فئي فئة

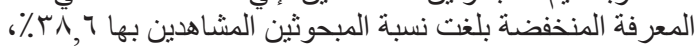

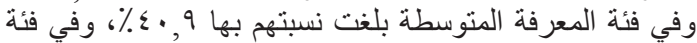

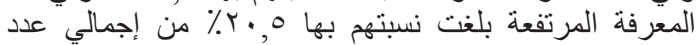

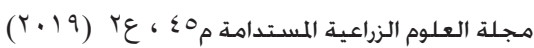




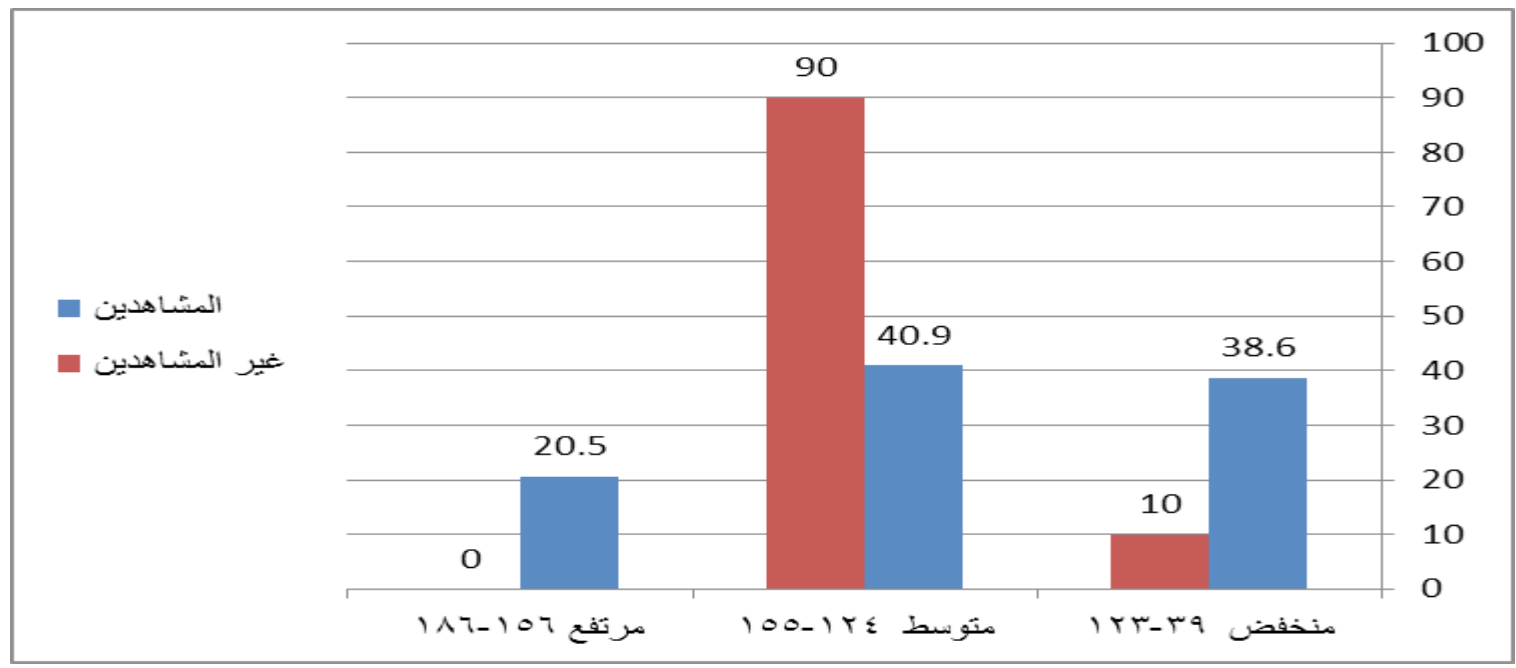

شكل 1 ـ توزيع المبحوثين المشاهدين وغير المشاهدين وفقا لارجة معرفتهم بمحتوى حلقات برنامج "حلقة وصل

جدول ؛. الفرق بين المبحوثين المشاهدين وغير المشاهدين فيما يتعلق بلرجة معرفتهم بالتوصيات الإرشادية المعروضة

اختبار قيمة T

\begin{tabular}{|c|c|c|c|c|c|c|c|}
\hline \multicolumn{2}{|c|}{ الجدولية } & \multirow[t]{2}{*}{ المحسوبة } & \multirow[t]{2}{*}{ أكبر قيمة } & \multirow[t]{2}{*}{ أقل قيمة } & \multirow[t]{2}{*}{ الالحعراف } & \multirow[t]{2}{*}{ الحستابي } & \multirow[t]{2}{*}{ العينة } \\
\hline$\cdot, \cdot 0$ & $\cdot, \cdot 1$ & & & & & & \\
\hline \multirow{2}{*}{1,97} & & & 19. & 1.7 & $r 0, r$. & $1 \leqslant \cdot, 1$ & المشاهدين \\
\hline &,-1 & Ne, & $1 \leqslant \varepsilon$ & 1.7 & $7,1$. & $\| v, \varepsilon$ & غير المشاهدين \\
\hline
\end{tabular}

المصدر : حسبت من استمار ات الاستبيان.

و اتضح أن قرابة وب٪ من المبحوثين المثاهدين جاءوا في التئي

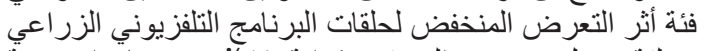

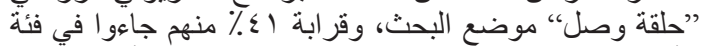

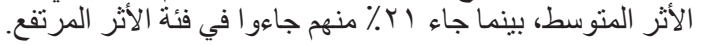

وتظهر هذه النتائج وجود أثراً واضحاً لمشاهدة المبحوثين

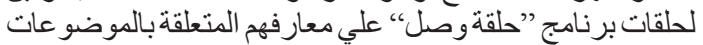
المعروضة من خلال هذا البرنامج مقارنة بارئنة بالمبحوثين غير

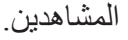

ولمزيد من التفصيل يتم استعر اض معرفة المبحوثين المشاهدين

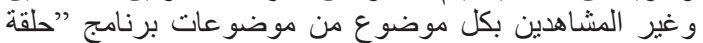
وصل،" على النحو التالي: 1 - المعرفة بموضو الفحو المكافحة الحبوية لحشرة المن:

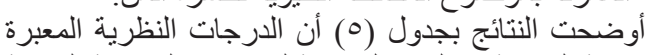

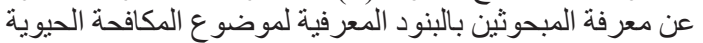

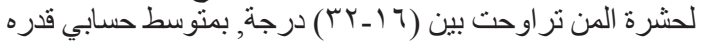

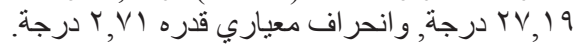

وتم تقسيم المبحوثين المشاهدين إلي ثلاث فئاتِ، فئة المعرفة

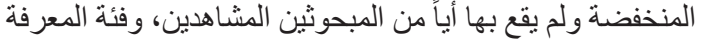

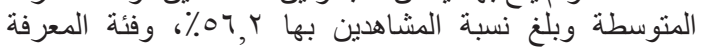

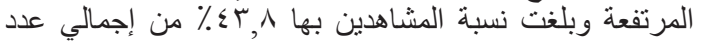

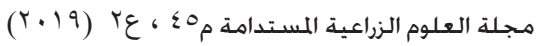

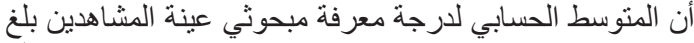

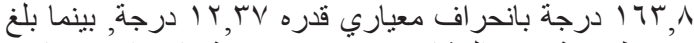

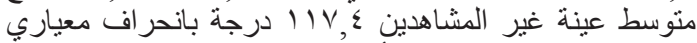

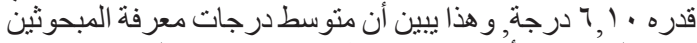

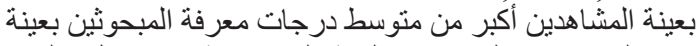

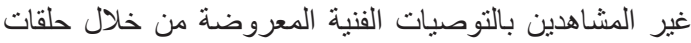

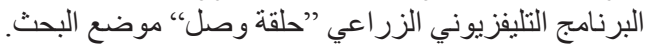

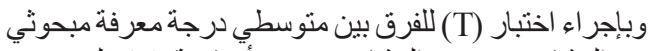

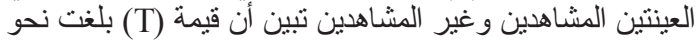

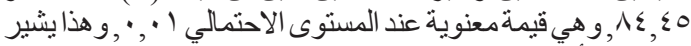

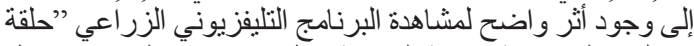

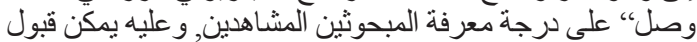

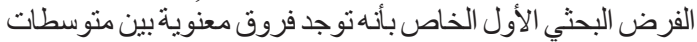

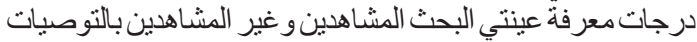

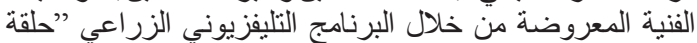
وصل"،

وكثفت النتائج بشكل (r) عن أن الدرجات المعبرة عن أثر

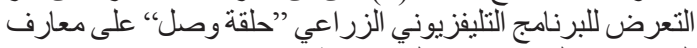

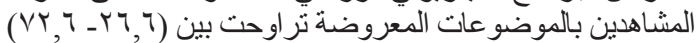

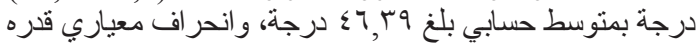

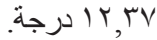




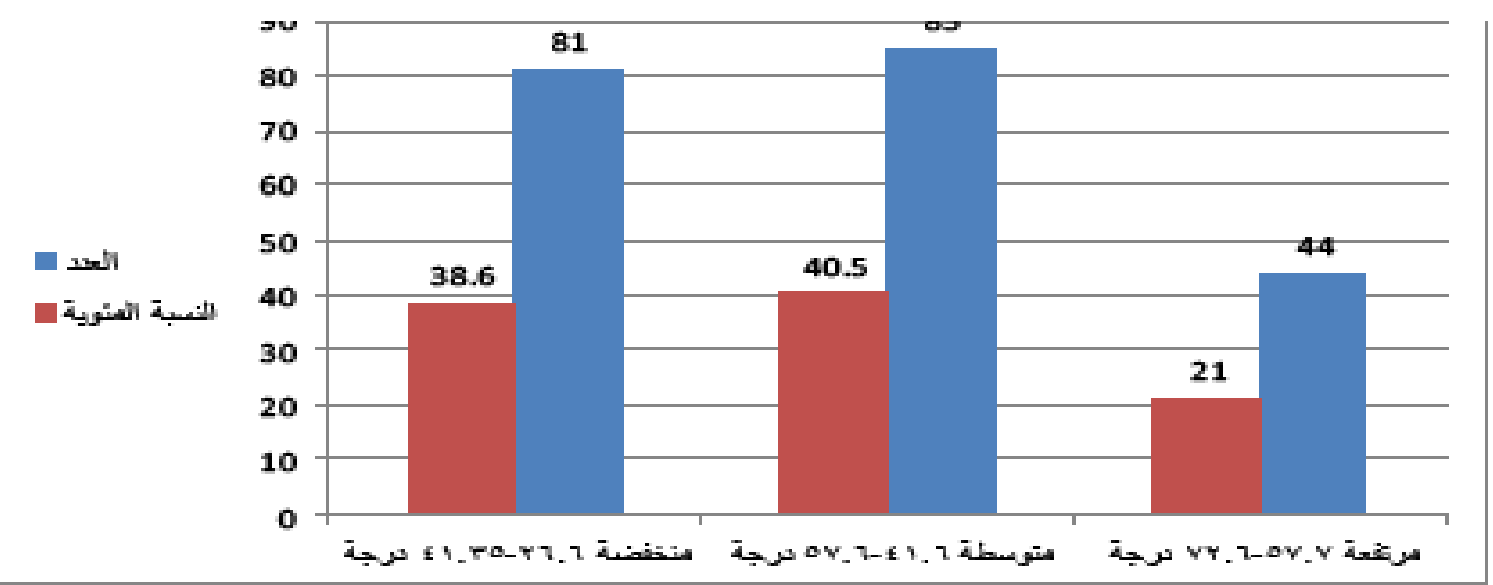

شكل ؟ أثر التعرض للبرنامج التليفزيوني الزراعي حلقة وصل على معارف المشاهدين بالموضوعات المعروضة

المصدر: حسبت من استمار ات الاستبيان

جدول هـ توزيع المبحوثين المشاهدين وغير المشاهدين وفقا لارجة معرفتهم بموضوع المكافحة الحيوية لحشرة المن

\begin{tabular}{|c|c|c|c|c|}
\hline \multicolumn{2}{|c|}{ غير المشاهدين } & \multicolumn{2}{|c|}{ المشاهدين } & \multirow{2}{*}{ موضوع المكافحة الحيوية لحشرة المن } \\
\hline$\%$ & عدد & $\%$ & عدد & \\
\hline$\vee r, \wedge$ & 100 & $\cdot, \cdot$ & صفر & منخفضة (7 ו- + ץ) درجة \\
\hline$r \leq, \wedge$ & or & $07, r$ & 111 & منوسطة (IV-YY) درجة \\
\hline $1, \varepsilon$ & r & $\varepsilon \Gamma, \wedge$ & $9 r$ & مرتفعة (^ץ-r -r) درجة \\
\hline $1 \cdots$, & $1 \mathrm{~V}$. & $1 \cdots$, & H. & الإجمالي \\
\hline
\end{tabular}

و ويتضح من النتائج السابقة أن جميع المبحوثين المشاهدين بنسبة

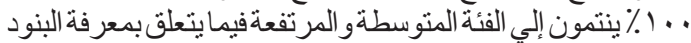

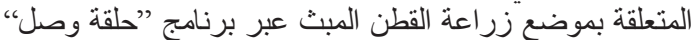

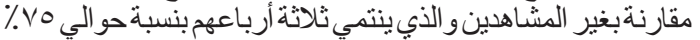

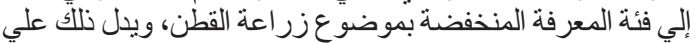
استفادة المبحوثين المشاهدين الكبيرة من مشاهدة حلقات المنات البرنامج

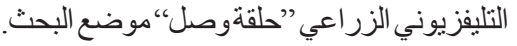
بـ المعرفة بموضو عزر اعة القمح:

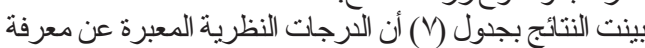

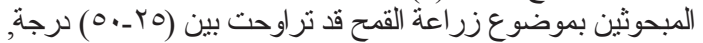

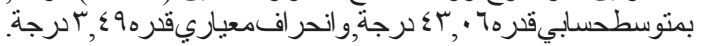
وبتقسيم المبحوثين المشاهدين إلي ثناتث فئات، فئة المعرفة فئة

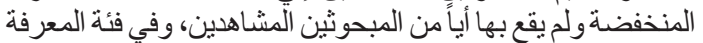

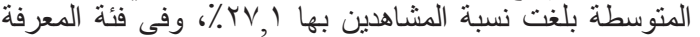

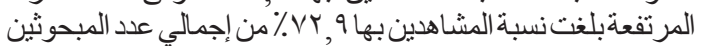
المشاهلين.

و وبتقسيم عينة المبحوثين غير المشاهدين فقد أظهرت النتائجبجدول

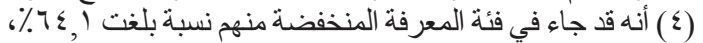

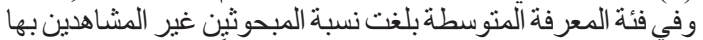

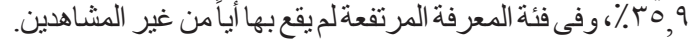

و ويتبين من النتائج السابقة أن جميع المبحوثين المشاهدين بنسبة

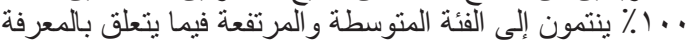

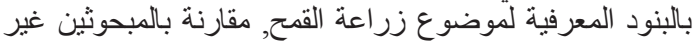

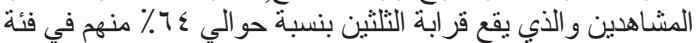

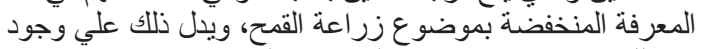
دور للبرنامج في رفع دعارف المبحوثين المشاهدين نتيجة مشّاهدتهم
المبحوثين المشاهدين.

بينما بالنسبة للمبحوثين غير المشاهدين فقد جاء في فئة

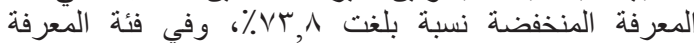

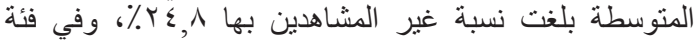

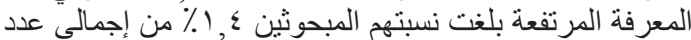
المبحوثين غير المشاهدين.

وتظهر النتائج السابقة أن جميع المبحوثين المشاهدين بنسبة

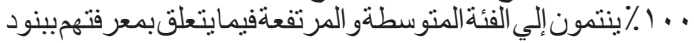

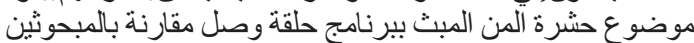

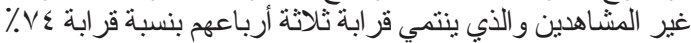

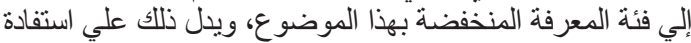
المبحوثين المشاهدين الكبيرة من مشاهدة حلقات المبات البرنامج التلايفزيوني

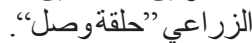

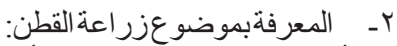

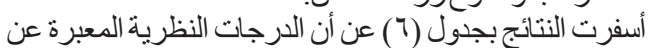

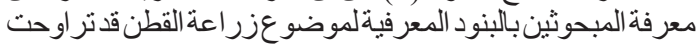

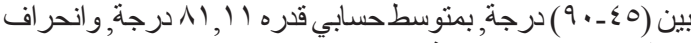

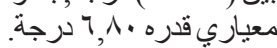

وبتقسيم المبحوثين المشاهدين إليثناث فئات، جاء في فئة المعرفة

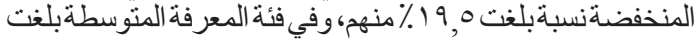

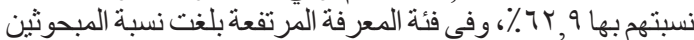

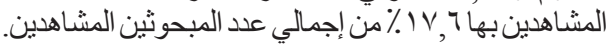

وبالنسبة لعينة المبحوثين غير المشاهدين أظهرت النتائج أنسبة

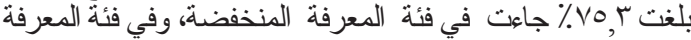

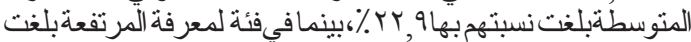

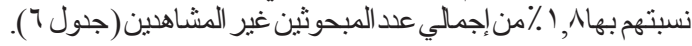

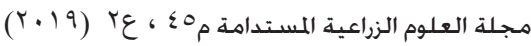


و تنظهر النتائج السابقة أن جميع المبحوثين المشاهدين بنسبة

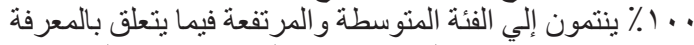

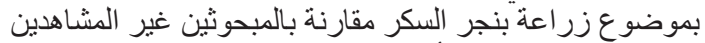

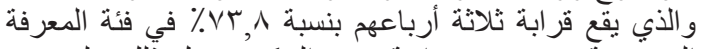

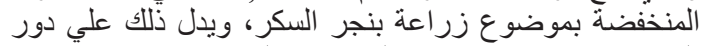

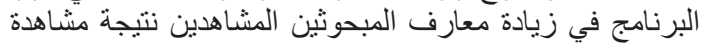

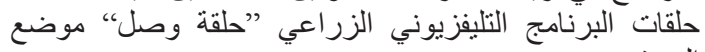
البحث.

ثالثاً: درجة كفاية المعلومات المتعلقة بمحتوى موضو عات حلقات

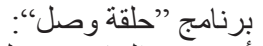
أوضحت النتائج بجدول (9) (9) أن الدرجات النظرية المعبرة

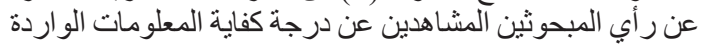

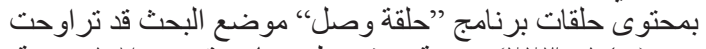

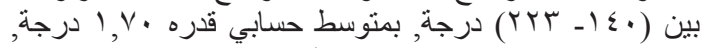

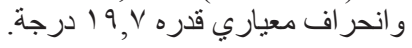

لحلقات البرنامج التليفزيوني الزر اعي ”حلقةوصل“، موضع البحث. عـ - المعرفة بموضو عزر اعة بنجر السكر :

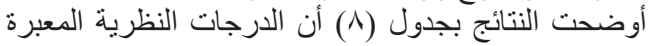

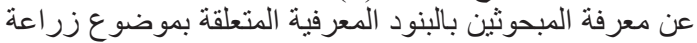

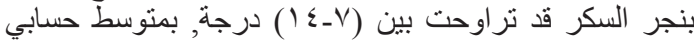

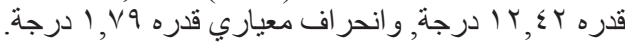

وبتقسيم المبحوثين المشاهدين إلي ثناث فئات، ففي فئة

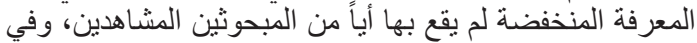

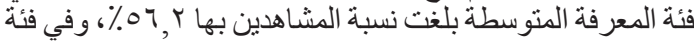

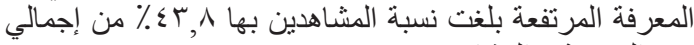
عدد المبحوثين المشاهدين.

وكشفت النتائج بجدول (^) عن أن نسبة المبحوثين المشاهدين

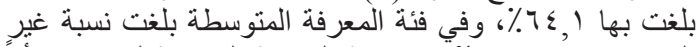

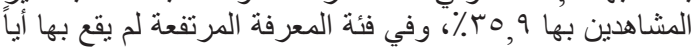

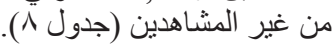

جدول 7 ـ توزيع المبحوثين المشاهدين وغير المشاهدين وفقا لارجة معرفتهم بموضوع زراعة القطن

\begin{tabular}{|c|c|c|c|c|}
\hline \multicolumn{2}{|c|}{ غير المشاهاين } & \multicolumn{2}{|c|}{ المشـاهدين } & \multirow{2}{*}{ فئات المعرفة بموضع زراعة القطن } \\
\hline$\%$ & عدد & $\%$ & عدد & \\
\hline$v 0, r$ & KN & $\cdot, \cdot$ & - & منخفضة (0ء _990) درجة \\
\hline$r, q$ & rq & ה, r & $v_{1}$ & 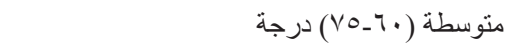 \\
\hline 1,1 & r & $77, r$ & 149 & 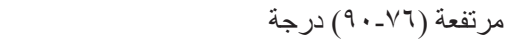 \\
\hline
\end{tabular}

جدول V. توزيع المبحوثين المشاهدين وغير المشاهدين وفقا لدرجة معرفتهم بموضوع زراعة القمح

\begin{tabular}{|c|c|c|c|c|}
\hline \multicolumn{2}{|c|}{ غير المشاهدين } & \multicolumn{2}{|c|}{ المشاهدين } & \multirow{2}{*}{ موضوع زراعة القمح } \\
\hline$\%$ & عدد & $\%$ & عدد & \\
\hline $7 \leqslant, 1$ & 1.9 & $\cdot$, & - & منخفضة (0 بـ וץ) درجة \\
\hline ro, 9 & 71 & $r v, 1$ & ov & متوسطة (r - • ع) درجة \\
\hline$\cdot, \cdot$ & · & $V r, q$ & 10r & مرتفعة (q ــــ) درجة \\
\hline $1 \cdots, \cdot$ & ive & $1 \cdots$, & YI. & \\
\hline
\end{tabular}

جدول ^. توزيع المبحوثين المشاهدين وغير المشاهدين وفقا لارجة معرفتهم بموضوع زراعة بنجر السكر

\begin{tabular}{|c|c|c|c|c|}
\hline \multicolumn{2}{|c|}{ غير المشاهدين } & \multicolumn{2}{|c|}{ المشاهدين } & \multirow{2}{*}{ موضوع زراعة بنجر السكر } \\
\hline$\%$ & عدد & $\%$ & عدد & \\
\hline$V r, \wedge$ & 100 & $\cdot, \cdot$ & $\cdot$ & منخفضة (A-V) درجة \\
\hline$r \leqslant, \wedge$ & or & $07, r$ & 111 & متوسطة(9-9 Y ) درجة \\
\hline $1, \varepsilon$ & $r$ & $\varepsilon r, \wedge$ & 94 & مرتفعة (س _ـ ا ) درجة \\
\hline $1 \ldots$ & IV. & $1 \ldots$ & Y. & الإجمالي \\
\hline
\end{tabular}

المصدر : حسبت من إستمار ات الاستبيان

جدول 9 ـ توزيع المبحوثين المشاهدين وفقاً لدرجة كفاية المعلومات الواردة بمحتوى برنامج "حلقة وصل،؛.

\begin{tabular}{|c|c|c|c|}
\hline$\%$ & 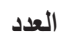 & درجة كفاية المعلومات & \\
\hline or, , & 111 & & منخفضة (•ـ (-47 1) درجة \\
\hline$r, \varepsilon$ & 71 & & منوسطة (77 (197 1) درجة \\
\hline $1 \mathrm{r}, \Lambda$ & rq & & 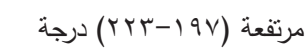 \\
\hline$\ldots$ & r. & الإجماليـ & \\
\hline
\end{tabular}

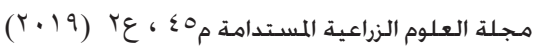




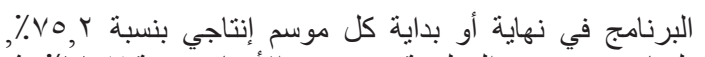

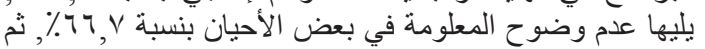

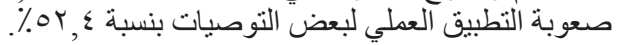

خامساً: مقترحات المبحوثين المشاهدين حول تطوير البرنامج

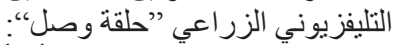

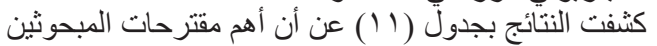

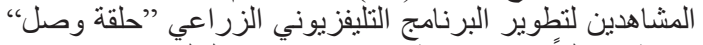

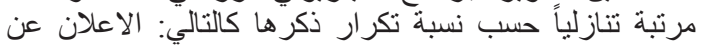

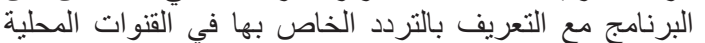
ومواعيد إذاعته بنسبة التعربف بالترد\%

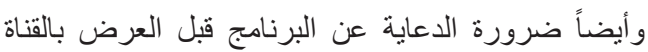

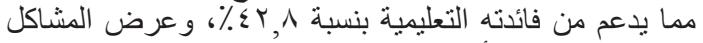

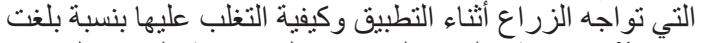

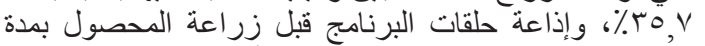

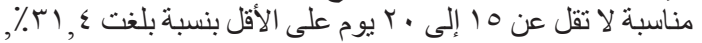

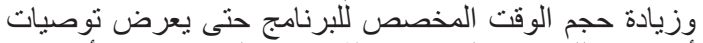

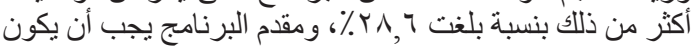

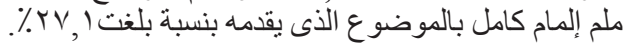

التوصيات

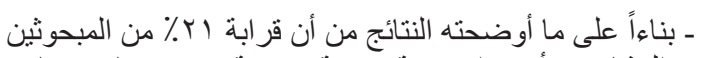

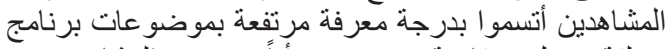

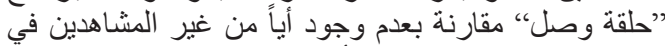

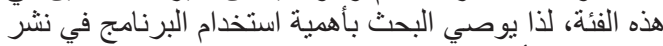

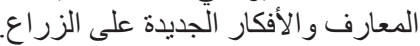

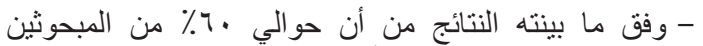

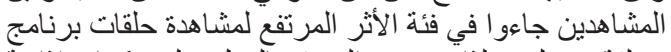

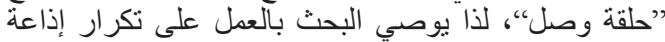

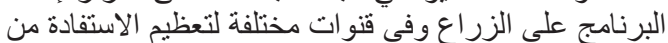
المعلومات التي يذيعها.
وتم تقسيم المبحوثين المشاهدين إلي ثلاث فئات، ففي فئة

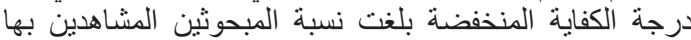

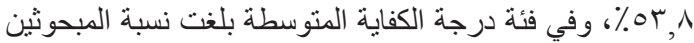

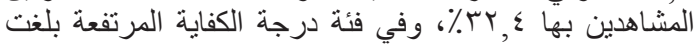

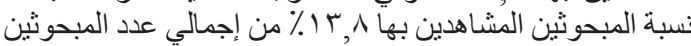

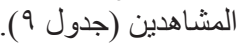

ويتضح من النتائج السابقة أن غالبية المبحوثين المشاهدين

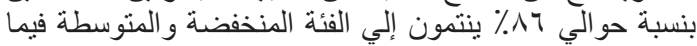

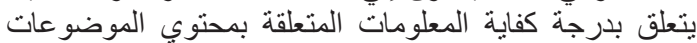

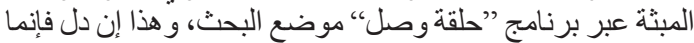

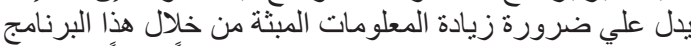

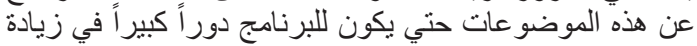

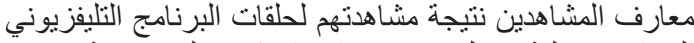

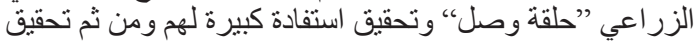
درجة عالية من رضا هؤ لاء المشاهدين.

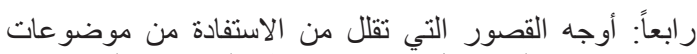

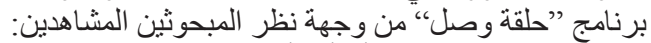

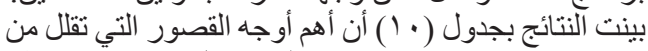

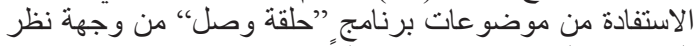

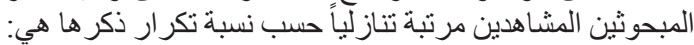

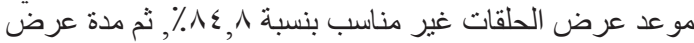

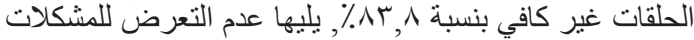

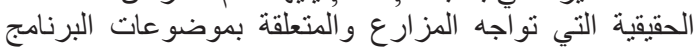

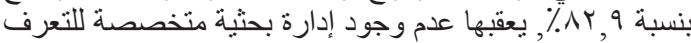

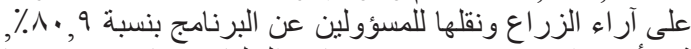

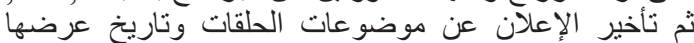

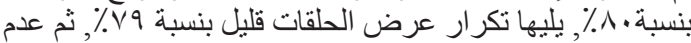

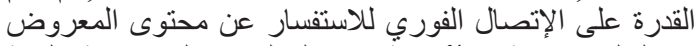

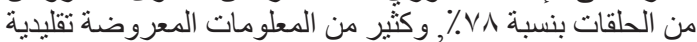

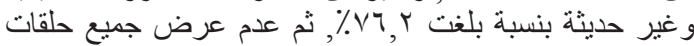

جدول ـ 1. توزيع المبحوثين المثاهدين وفقاً لأوجه القصور التي تقلل الاستفادة من موضوعات برنامج ”حلقة وصل،

\begin{tabular}{|c|c|c|}
\hline$\%$ & 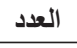 & أوجه القصور \\
\hline$\wedge \varepsilon, \wedge$ & iv & موعد عرض الحلقات غير مناسب \\
\hline$\wedge r, \wedge$ & 187 & مدة عرض الحلقات غير كافي \\
\hline$\wedge r, q$ & $1 v \leq$ & عدم التعرض للمشكلات الحقيقية التي تواجه المزارع والمتعلقة بموضوعات البرنامج \\
\hline$\wedge \cdot, 9$ & ive & عدم وجود ادارة بحثية متخصصة للتعرف على اراء الزراع ونقلها للمسؤولين عن البرنامج \\
\hline$\wedge \cdot, \cdot$ & 171 & تأخير الاعلان عن موضوعات الحلقات وتاريخ عرضها \\
\hline$\vee १, \cdot$ & 174 & تكرار عرض الحلقات قليل \\
\hline$\vee \wedge, \cdot$ & $17 \varepsilon$ & عدم القدرة على الاتصال الفوري للاستفسار عن محتوى المعروض من الحلقات. \\
\hline$v 4, r$ & 17. & كثير من المعلومات المعروضة تقليدية وغير حديثة \\
\hline vo,r & 101 & عدم عرض جميع حلقات البرنامج فى نهاية أو بداية كل موسم إنتاجي \\
\hline $77, \mathrm{~V}$ & $1 \leqslant$ & عدم وضوح المعلومة في بعض الأحيان. \\
\hline or, $\varepsilon$ & 11. & صعوبة النطبيق العملي لبعض التوصيات. \\
\hline$\leqslant r, q$ & 9. & عدم الثقة في مصدر المعلومة \\
\hline$\varepsilon \cdot, 9$ & $\wedge \mathrm{T}$ & عدد المنتج من حلقات البرنامج قليلة \\
\hline$r r, r$ & $v \cdot$ & عدم عرض جميع حلقات البرنامج في نهاية او بداية كل موسم إنتاجي \\
\hline$\uparrow \wedge, \uparrow$ & 7. & عدم توفر حلقات البرنامج فى صورة اسطوانات للاستعارة او الثراء \\
\hline
\end{tabular}

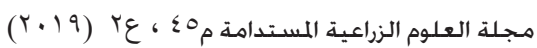


جدول الـ توزيع المبحوثين المشاهدين وفقا لمقترحاتهم لتطوير البرنامج التليفزيوني الزراعي "حلقة وصل،؛.

\begin{tabular}{|c|c|c|}
\hline$\%$ & 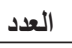 & المقترحات \\
\hline ov, 1 & ir. & - الاعلان عن البرنامج مع التعريف بالتردد الخاص بها فى القتوات المحلية ومواعيد إذاعته \\
\hline$\leqslant \curlyvee, \wedge$ & 9. & - ضرورة الدعاية عن البرنامج قبل العرض بالقناة مما يدعم من فائدنه التعليمية \\
\hline ro, & vo & - عرض المشاكل التي تواجه الزراع اثناء التطبيق وكيفية التغلب عليها. \\
\hline$\mu^{1, \varepsilon}$ & 74 & - اذاعة حلقات البرنامج قبل زراعة المحصول بمدة مناسبة لا تقل عن 10 الى • ب يوم عل الاقل. \\
\hline$r \wedge, \uparrow$ & 7. & - زيادة حجم الوقت المخصص للبرنامج حتى يعرض نوصيات اكثر من ذلك. \\
\hline$r v, 1$ & ov & - مقدم البرنامج يجب أن يكون ملم المام كامل بالموضوع الذى يقدمه. \\
\hline$r \varepsilon, r$ & 01 & - تطوير المحتوى وايجاد اشخاص متعلمة ومتخصصة فى العمل الزراعي \\
\hline r r, A & $\varepsilon \wedge$ & - يقدم البرنامج بصوت هادئ ومتزن مع عرض الصور من خلفه. \\
\hline r & «o & - استخدام البرنامج للتعليقات الفكاهية فى هذا البرنامج تجعل منه فقرة خفيفة مستحبة للمشاهدين \\
\hline $\mid v, 1$ & 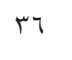 & - ضرورة المشاركة الفاعلة للزراع من خلال الدخلات التليفونية بالبرنامج لزيادة فاعلية البرنامج. \\
\hline $10, v$ & re & - عرض تقنيات زراعية جديدة لتوفير مياه الري. \\
\hline $1 \varepsilon, r$ & r. & 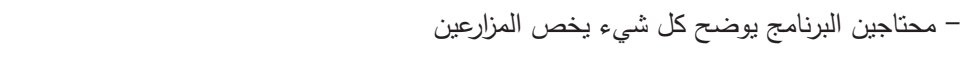 \\
\hline $11, \varepsilon$ & $r \leq$ & - وضع الية شهرية للحلقات تعتمد على الاهداف التعليمية الزراعية لرفع مستوى الزارع المشاهدين \\
\hline$\wedge, 7$ & 11 & -الاهتمام بالأساليب والتقنيات الزراعية الحديثة لزيادة الانتاجية ورفع الروح المعنوية للمزارعين. \\
\hline
\end{tabular}

الريف، دار الكتب الجامعية، الإسكندرية.

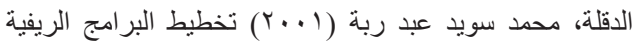

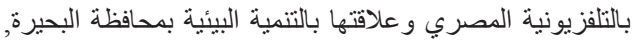

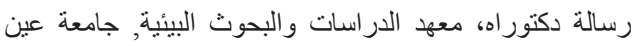

شمس.

الديب، أحمد دياب عيد (T) (1) إسهام البرامج التلفزيونية

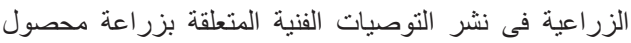

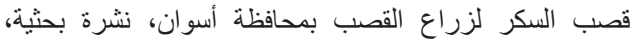

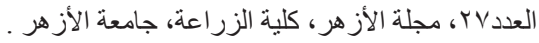

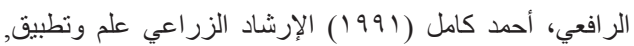

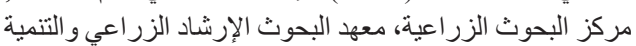

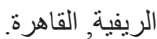

السيد، محمد عبد الجليل فرج( (999 19 ) دراسة في فعالية البر امج الريفية

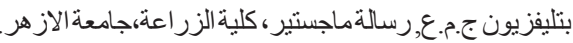

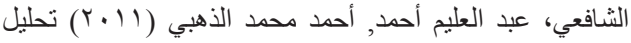

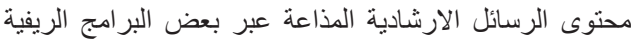

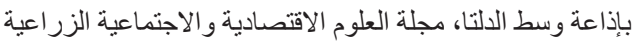
كلية الزر اعة جامعة المنصورة، مجلد (Y ) )، عدد (l (l) ) نوفمبر.

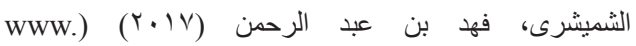
(saudimediaeducation.org/index

الصياد، عبد الباسط محمد (r . . . ) وسائل الاعلام الريفي، مصر

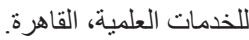

العادلي، أحمد السيد (TVY (1) ) أساسيات علم الإرشاد الزر اعي، دار المطبو عات الجديدة، الإسكندرية.

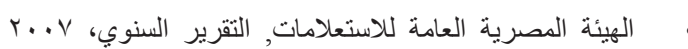

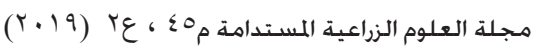

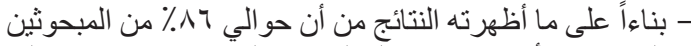

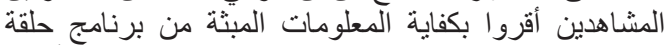

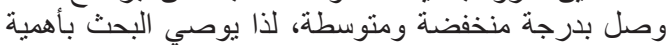

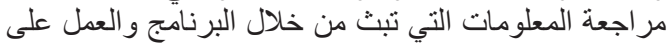

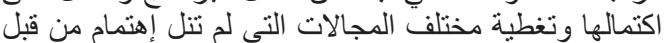

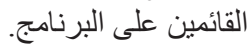

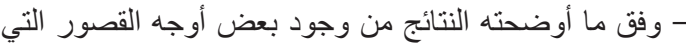

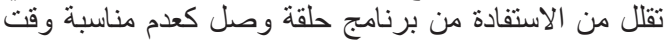

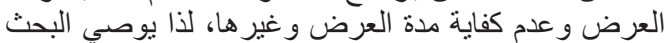

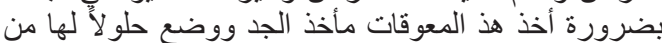
أجل زيادة درجة الاستفادة من إذاعة حلقات برنامج حلقة حلة وصل.

المـراجـع

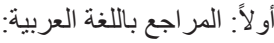

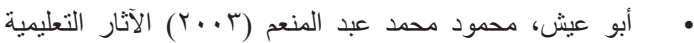

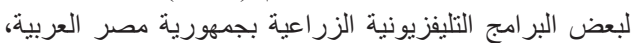
رسالة دكتوراه، قسم الارشاد الزراعي، كلية الزراعة اعنة بمشتهر، جامعة الزقازيق فرع بنها. التهامي، مختار (9V0) (1900 تحليل مضمون الدعاية بين النظرية و التطبيق, دار المعارف، القاهرة.

الجنجيهى، هدى محمد (9191) المطبوعات الإرشادية في

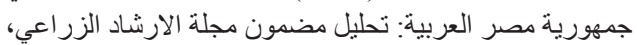
رسالة دكتور اه، كلية الزر اعية، جامعة القاهرة .

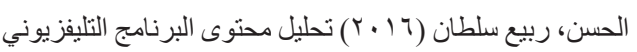

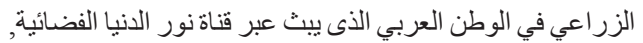
رسالة دكتور اه, كلية الزر اعة، جامعة القاهرة. • الخولى، حسين زكى (9VV ) الإرشاد الزر اعي، دورة في تطوير 


$$
\text { البحوث الزر اعية, عددّ, مجلد؛. }
$$

فهيم، فوزية (ع ا9 1) المادة الإخبارية في الإذاعة المصرية.

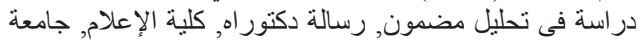

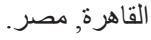

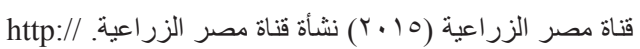
www.misraIzraya.tv@.com.1/11/2015

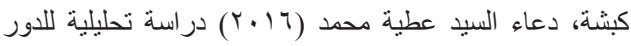

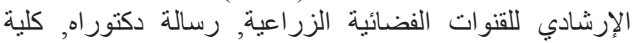

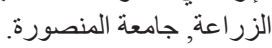

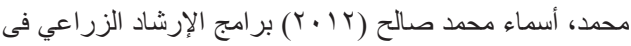

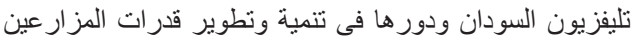
(www.repository.sustech.edu/handIe)

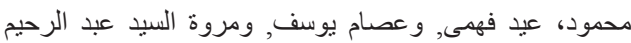

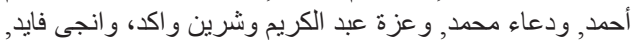

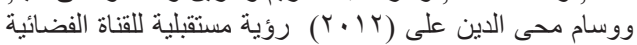
الزراعية المصرية، مركز البحوث الزئ الزراعية, معهد بحوث الارشاد الزر اعي و التنمية الريفية.

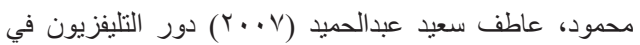

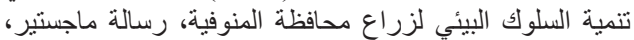
غير منشورة، كلية الزراعة، جامعة الأز هر بالقاهرة.

مركز الدعم الإعلامي للتنمية بمريوط, دراسة أبعاد الدور

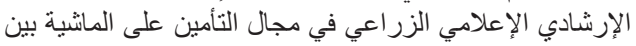

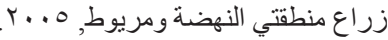

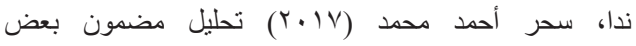

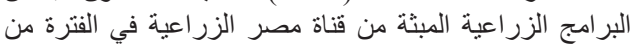

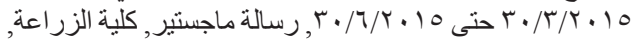

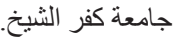

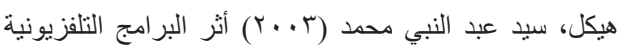

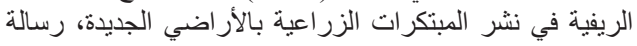

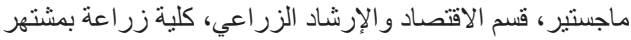

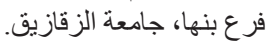

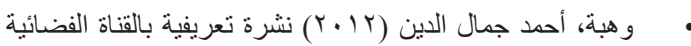
الزر اعية, بيانات غير منشورة.

ثانيا: المراجع باللغة الإنجليزية: - مانية

- Eudd, Richard thorp, Robert \& Donohew, Lewis (1967) Content Analysis of Communications, New York, the Macmillan Company.

- Holsti, Ole. (1969) Content Analysis for the Social Sciences and Humanities, Addison Wesley.

- Swanson, B. (ed) (1990) Agricultural Extension, Reference Manual, F.A.O., Rome.

- TayIor, E. and Renner, m.(2003) Analyzing Qualitative Data, Extension Program Development \& Evaluation, University of Wisconsin,p.12.

-http//Iearningstore.uwex.edu/assets/pdfs/\&3658-12. pdf. 28-1-2016. http//www.sis.gov.: تقرير منشور على الموقع الإلكتروني eg/ar/story.aspx?sid=3420

حسن، هند حسنى على (ع ا • ب) تحليل الموقف الر اهن للإعلام

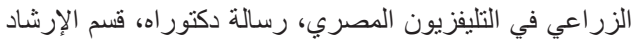
الزر اعي، كلية الزر اعة، جامعة أسيوط. حسين، سمير محمد (r (911) تحليل المضمون، دار الكتب، القاهرة.

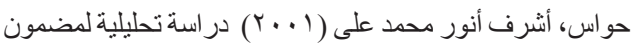

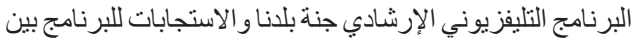

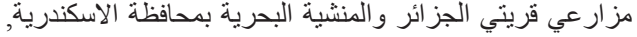
رسالة ماجستير, كلية الزر اعة وائر جامعة الاسكندرية.

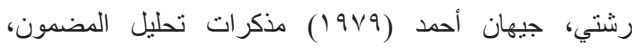
الدراسات العليا كلية الزر اعة، جامعة القاهرة

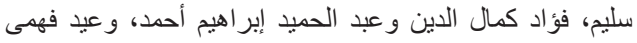

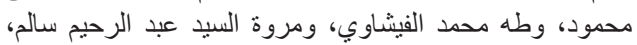

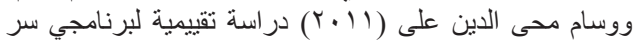
الأرض و التنويهات الارشادية الزر اعية واستطلاع ر رأى في انشاء قناة فضائية زر اعية مصرية.

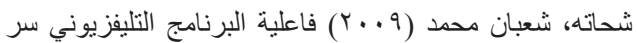

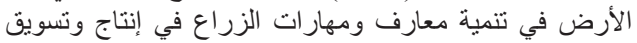

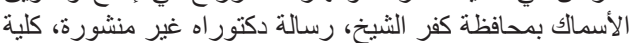
الزر اعة بالقاهرة، جامعة الأزهر هر.

طلعت, شاهيناز محمد (990 (190) وسائل الإعلام و التنمية الاجتماعية دراسات نظرية مقارنة وميدانية في المجتمع الريفي, مكتبة الأنجلو الألو مصرية, القاهرة, الطبعة الثالثة.

عبد الحميد، محمد (ب/9 (1) تحليل المضمون في بحوث الاعلام

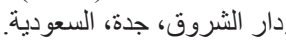

عبد الغفار ، عبد الغفار طه (9V7 (9V7) الإرشاد الزر اعي بين الفلسفة و التطبيق، دار المطبو عات الجديدة، الإسكندرية.

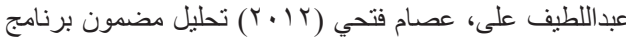

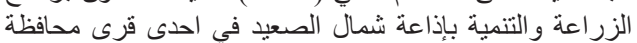

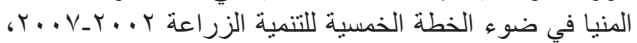
رسالة دكتور اه، كلية الزر اعة، جامعة القاهرة.

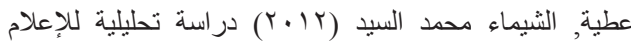

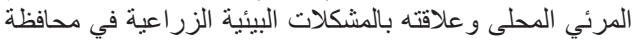

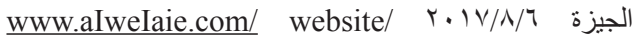
university theses

عمر ، أحمد محمد (·191) الإرشاد الزراعي، أوفيستا للطباعة،

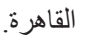

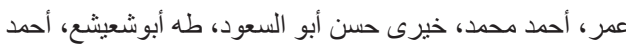

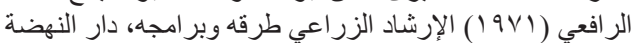

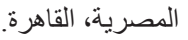

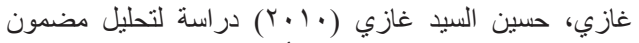

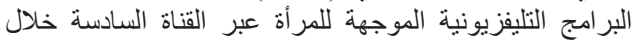

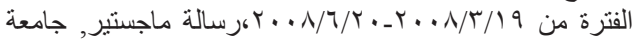

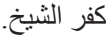

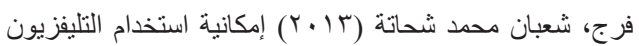

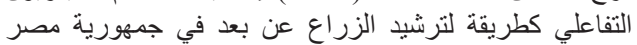

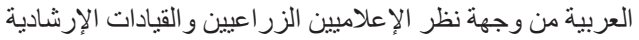
و القيادات الزر اعية, معهد بحوث الإرشاد و التنمية الريفية، مركز الزرئر

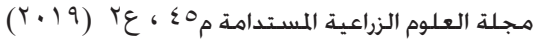




\section{Evaluation of The Impact of The Agricultural Television Program \\ "Halaket Wasl" Presented to The Rural People at Kafr El-Sheikh \\ Governorate}

Adel Ibrahim Elhamoly, Manal Fahmey Ali and Mahmoud H. Mohamed

Agricultural Economic Dept., Agr. Ext., Kafrelsheikh Univ.,Egypt

$\mathbf{T}$

HIS RESEARCH was mainly aimed at evaluating the impact of the agricultural television program "Halaket Wasl" transmitted through the of space agricultural Egypt channel provided to rural people at Kafr El-Sheikh governorate during the period from 30/3/2017 until 30/6/2017. The research was conducted in Kafr El-Sheikh governorate. It selected two Beiala and Elhamoul districts. The Ibshan, Kom El-Hajna, Al-Zaafran and Al-Kafr Al-Sharqi villages were selected from these two districts. The first sample size of farmers was 210 respondents watching sessions program of the "Halaket Wasl". The second sample who non- watching were second sample about 170 respondents. The main findings of the research were as follows: There were significant differences between the two research samples based on the value of $\mathrm{T}$ (test) of about 84.45 , which is a significant value at the probability level 0.01 , indicating that there is a clear effect to watch the agricultural television program "link" to the degree of knowledge of the sample Viewers. About $86 \%$ of the low and medium categories were identified as to the adequacy of information on the content of the topics posted via a link program.

Key wards: Evaluation, Television, Impact, Program, Rural, Farmer, People 